Portland State University

PDXScholar

Summer 8-28-2018

\title{
Examining the Spatial Characteristics of Pluvial Flooding Through Citizen Science in Portland, Oregon
}

Katelyn Rachel Michelson

Portland State University

Follow this and additional works at: https://pdxscholar.library.pdx.edu/open_access_etds

Part of the Geography Commons

Let us know how access to this document benefits you.

\section{Recommended Citation}

Michelson, Katelyn Rachel, "Examining the Spatial Characteristics of Pluvial Flooding Through Citizen Science in Portland, Oregon" (2018). Dissertations and Theses. Paper 4548.

https://doi.org/10.15760/etd. 6433

This Thesis is brought to you for free and open access. It has been accepted for inclusion in Dissertations and Theses by an authorized administrator of PDXScholar. Please contact us if we can make this document more accessible: pdxscholar@pdx.edu. 
Examining the Spatial Characteristics of Pluvial Flooding Through

Citizen Science in Portland, Oregon

by

Katelyn Rachel Michelson

A thesis submitted in partial fulfillment of the requirements for the degree of

Master of Science

in

Geography

Thesis Committee:

Heejun Chang, Chair

Amy Lubitow

David Banis

Portland State University

2018 


\begin{abstract}
Pluvial flooding is caused by rainfall events that overwhelm drainage systems and do not allow excess water to be absorbed by soils or water infrastructure. This type of flooding occurs frequently in urban systems and leads to public inconveniences and infrastructure deterioration, which could cost more than fluvial flooding over time. Increased rainfall intensity, which is projected to increase with climate change, could result in increased pluvial flooding. This study aims to examine the vulnerability of pluvial flooding in Portland, OR (20102017) by incorporating an interdisciplinary framework that examines the physical and socioeconomic vulnerability of flooding through citizen-reported flooding data. We use a spatially dense network of 5-minute interval rainfall measurement to examine 3-day storm events associated with flooding reports to correlate storm size with the frequency of reports. Additionally, we use a Topographic Wetness Index (TWI) to identify the hotspots of pluvial flooding over space and characterize the sociodemographic and building characteristics of hotspots by performing a spatial analysis using census tract and tax lot level data. We investigate how individual neighborhood characteristics (i.e. ethnicity, education, gender, age, income) and building characteristics (i.e. building type, building age) contribute to reported flooding. This research seeks to identify where pluvial flooding occurs across the city, and how flood management planning can better address flood vulnerability through the biophysical and socioeconomic characteristics that exists amongst communities in Portland.
\end{abstract}




\section{Acknowledgements}

In developing this thesis document, I would like to give the upmost praise to my advisor, Heejun Chang, for endless support, guidance and critique of my thesis along the way. This document would not be possible without Heejun's prompt and consistent feedback of my work. I am also very grateful to the constant support and ideas from my committee members David Banis and Amy Lubitow who offered great suggestions and guidance along the way.

I would like to express extreme gratitude to the City of Portland, Bureau of Environmental Services (BES) for allowing this thesis project to be possible. I would like to thank Nicolas McCullar and Shannon Reynolds of BES for access to the City's citizen-observed flooding dataset and many initial ideas in the development of this project. I would also like to thank Fred MacGregor and Shannon Axtell of BES who helped guide the bulk of this analysis from a city stormwater perspective and consistently offered their support and time in completing this project.

Lastly, I would like to thank the Institute of Sustainable Solutions (ISS) at Portland State University who supported my thesis from the very beginning and facilitated the collaboration with BES throughout the project. 


\section{Table of Contents}

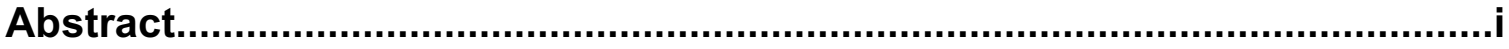

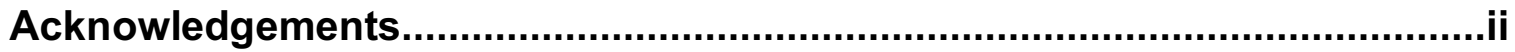

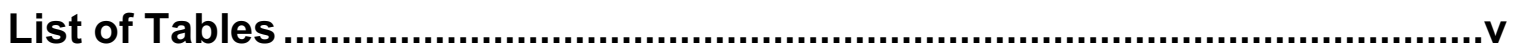

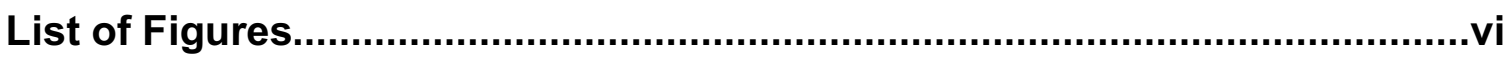

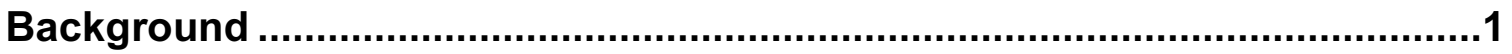

Research Objective and Questions........................................................... 6

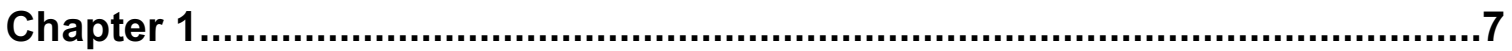

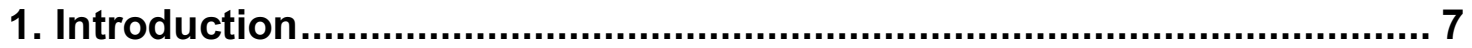

2. Study Area

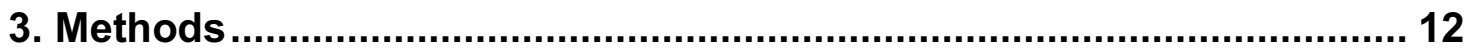

3.1 Data Collection and Processing ................................................. 12

3.2 Correlating citizen-observed flooding reports with storm events ........... 14

3.3 Spatial distribution of flooding reports ........................................... 16

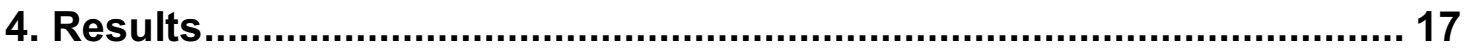

4.1 Frequency of flooding reports per 3-day storm size .......................... 17

4.2 Spatial analysis of flooding reports by different periods of the wet season

20

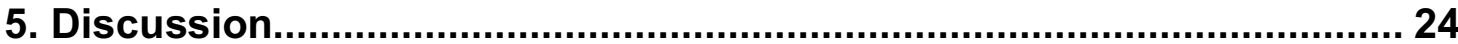

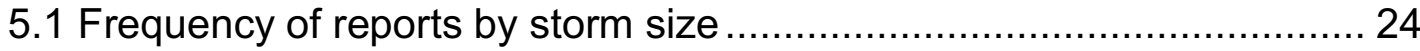

5.2 Spatial distribution of flooding reports ............................................ 25

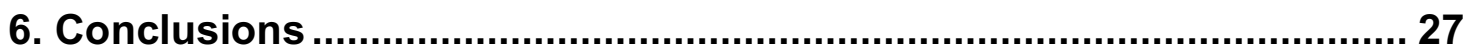

Chapter 2

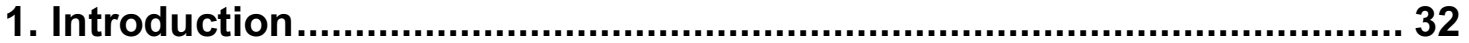

2. Study Area

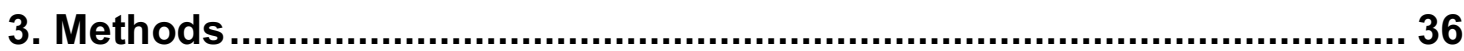

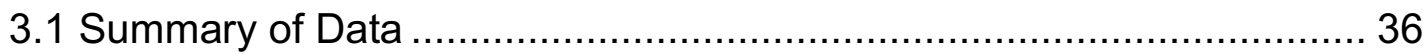

3.2 Correlation-TWI and flood report density ......................................... 40

3.3 Regression Analysis-Flood reports and socio-demographic and building

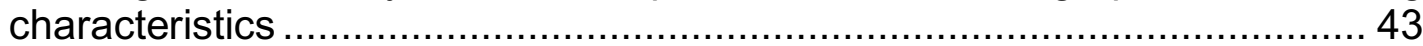

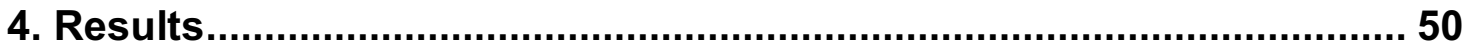

4.1 TWI and Flood Report Correlation ................................................. 50

4.2 Flood Reports and Socio-demographic and Building Characteristics.... 53

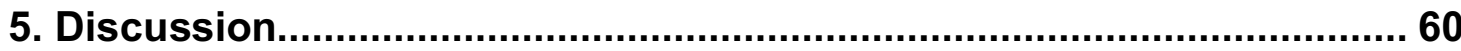

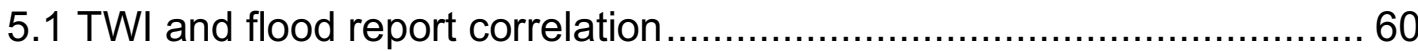


5.2 Socio-demographic and building characteristics of flood reports 61

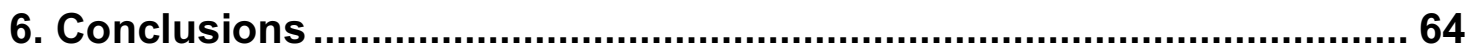

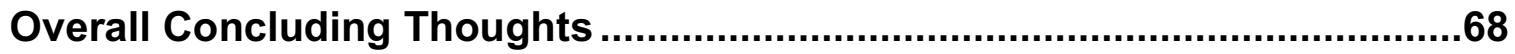

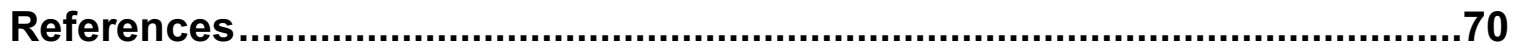

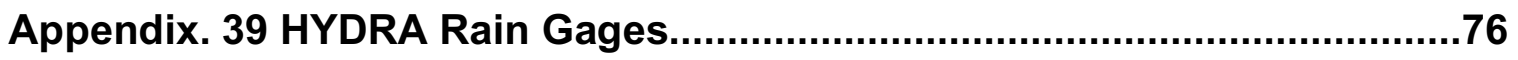




\section{List of Tables}

Table 1: Categorization of citizen-observed flooding reports in City TrackIT database

Table 2: Summary of data used in analysis

Table 3: List of 17 explanatory variables used in analysis. Indicating the Spearman Rank Correlation Coefficient, significance value (Sig.), Variance Inflation Factor (VIF) and number of observations (N).

Table 4: Correlation of mean flood report density and topographic wetness index (TWI) estimate at 5-acre hexagon and census tract scale. Table indicates the Spearman Rank Correlation Coefficient and Moran's I, and the significance of these two values. 51

Table 5: Statistical comparison between OLS and Spatial Lag Regression models:

Table 6: Statistical comparison between OLS, Spatial Lag and GWR models... 58 


\section{List of Figures}

Figure 1: Map of the three sewer systems across Portland. Purple indicates the combined sewer system, grey is the Sumps/UICs, and the yellow to brown tones are the separate sewer system regions (City of Portland 2010) ....................... 8

Figure 2: Study area map of Portland, OR …............................................ 10

Figure 3: Methodology of associating HYDRA rain gages with flood reports based on Thiessen polygons

Figure 4: a) total flooding reports ( $\mathrm{n}=9804)$ from 2010-2017 at different 3-day storm sizes $(\mathrm{cm})$, b.) Ratio of flooding reports over the total calendar days per 3day storm size $(\mathrm{cm})$

Figure 5: Maps of the density of reported flooding from 2010-2017. a) Oct-Dec. reports. b) Jan.-Feb. reports. c) March-April reports. d.) May-Sept. reports....... 22

Figure 6: Study area map of Portland, Oregon............................................ 35

Figure 7: Density of flood reports per census tract (square meters) and the six major quadrants of Portland.

Figure 8: Mean Topographic Wetness Index (TWI) estimate at 5-acre hexagon scale

Figure 9: Spatial patterns of five predicator variables used in final model. a) Percent age 25+ without a bachelor's degree b) Percent households with children under $18 \mathrm{c}$ ) Mean Age of Single-Family Residential buildings d) Mean age of commercial buildings e) Percent renters

Figure 10: LISA cluster maps of flood report density and TWI at 5-acre hexagon scale. Red indicates positive spatial autocorrelation and blue indicates negative spatial autocorrelation, while light blue and light pink indicate spatial outliers. a) Mean TWI and mean flood report density. b) Max TWI and mean flood report density 
Figure 11: LISA cluster maps of flood report density and TWI at census tract scale. Red indicates positive spatial autocorrelation and blue indicates negative spatial autocorrelation, while light blue and light pink indicate spatial outliers. a) Mean TWI and mean flood report density. b) Max TWI and mean flood report density. c) \% TWI estimates within two standard deviations and mean flood report density. d) Top $10 \%$ of TWI estimates and mean flood report density .... 52

Figure 12: Significant coefficients from the GWR model. a) Percent of population age 25+ without a BA. b) Percent of households with children under 18 years of age. c) Mean age of single-family residential (SFR) buildings. d) Mean age of commercial buildings

Figure 13: GWR model outputs. a) Local R-squared b) standardized residuals. 59

Figure 14: City of Portland, Bureau of Planning and Sustainability (BPS) Economic Vulnerability Assessment Map. Four risk factors are scaled from 0-16, with 0 being the lowest vulnerability and 16 the highest vulnerability (Bates 2013) 62 


\section{Background}

This research explores the spatial characteristics of urban flooding in Portland, Oregon (OR) through three interdisciplinary frameworks that examine the physical and sociodemographic vulnerability to flooding through citizenreported flooding data. Flooding within the context of this research refers to small-scale urban flooding known as pluvial or nuisance flooding, which is caused by either short, intense rainfall events or a steady duration of rainfall events that overwhelm drainage systems and do not allow excess water to be absorbed by soils or water infrastructure. Unlike large-scale river flooding, fluvial flooding, which can be attributed to 50-year and 100-year storm events, pluvial flooding occurs frequently in urban systems and leads to public inconveniences such as traffic congestion, building infrastructure deterioration, sewer system overflows and basement sewer backups. While previous research has focused on quantifying the damages and costs associated with fluvial flooding events, little attention has been given to pluvial flooding events that occur more frequently and could be costlier than fluvial flooding events over time (Moftakhari et al. 2015, Moftakhari et al. 2017).

Portland, OR. is known for its large-scale flooding events as the Willamette River experienced notable and severe flooding events during the 1800s and 1900s from lack of proper water infrastructure (Laenen \& Dunnette 1997). Some of the most notable flooding events within the current city boundary 
have been the flood of 1894, the Vanport floods in 1948 and the flood of 1996 which all caused massive damages to city infrastructure, industry, and human and animal life (Oregon Historical Society 2018). Although these events were much larger than pluvial flooding events, it is important to acknowledge the impact of increases in precipitation intensity that fluctuate seasonally and the need for proper stormwater infrastructure which could leave Portland vulnerable to more localized flooding events over time (Cooley \& Chang 2017).

Furthermore, the population in Portland has increased by $9.6 \%$ from 2010 to 2016 (U.S. Census Bureau 2016), and the addition of more buildings (i.e. impervious surface) does not allow water to infiltrate the soil and exacerbates flood risk. Consequently, this causes more runoff to overwhelm storm drainage systems and creates overland flow (Chang \& Franczyk 2008, Hailegeorgis \& Alfredsen 2017). While Portland has a fairly advanced and efficient stormwater management system in place, localized pluvial flooding events still occur across the system, and there is a lack of certainty in the spatial location of these events.

City stormwater engineers have been able to create predictive models of flood risk using hydraulic and hydrologic modeling, but have not been able to validate these models with citizen-generated reports of where flooding actually occurs across the system. For this reason, it is important to understand the correlation between predictive flood models and flooding data, which can be best reported by individuals on the ground who actually experience flooding issues (Fazeli et al. 2015, Singh 2014). Comparing predictive models based on 
topography of the urban system with citizen-observed data creates a better understanding if the models are accurately predicting where flooding predominantly occurs, and gives citizens a participatory role in flood management planning.

The main component of this study is the use of citizen-observed flooding data to understand where pluvial flooding occurs in Portland. This type of research draws on concepts of citizen-science, which refers to projects in which volunteer's partner with scientists to answer real-world questions (Cornell University 2018). Citizen-science accounts for citizens observing natural events and scientists using these observations to advance understanding, which is what this study aims to do. Additionally, the use of participatory spatial data has become increasingly relevant for visualizing natural hazards through Geographic Information Systems (GIS), as fields such as Participatory GIS (PGIS) and Voluntary Geographic Information (VGI) have emerged within the realm of spatial analysis (Fazeli et al. 2015, Hung et al. 2016, Klonner et al. 2016, Singh 2014, Uson et al. 2016).

PGIS refers to the involvement of local communities contributing information that can be used within GIS and spatial decision-making which affects these communities (Dunn 2007). VGI was coined by Goodchild in 2007 and refers to user-generated geographic information, as a way of creating, assembling, and disseminating geographic data provided by volunteers (Fazeli et al. 2015). Multiple studies have explored how PGIS and VGI can be effective in 
geospatial analyses of natural hazards, as it incorporates local knowledge, personal experiences and more relevant georeferenced information (Fazeli et al. 2015, Klonner et al. 2016). Unlike typical static flood hazard mapping that relies on morphological approaches, remote sensing and simulation methods, PGIS and VGI offer researchers the ability to constantly review and update spatial data of flooding events that occur rapidly (Fazeli et al. 2015). Previous studies have explored the different levels of participatory spatial data through crowdsourcing, distributed intelligence, participatory science and citizen science, and noted the benefits of having access to various sources of spatial data to accurately assess disaster management strategies (Hung et al. 2016, Klonner et al. 2016).

In addressing social vulnerability to natural hazards, there could be potential inequalities associated with communities most impacted by pluvial flooding as marginalized populations could be more impacted by natural disasters over time. While previous studies have indicated that the effects of climate change will be unequally felt by less-developed countries (LDC), research has also shown the unequal spatial distribution of flooding impacts on marginalized communities in the U.S. by examining three key components of social vulnerability: exposure, sensitivity, and adaptive capacity (Denton 2002, Douglas et al. 2012, Ge et al. 2017). Adapting to changes in climate and the repercussions of flooding requires a prior knowledge of how the climate is changing and resources to cope with natural hazards. Socioeconomic differences 
between communities could create a divide between individuals who will be most impacted by flooding over time (Douglas et al. 2012).

The three frameworks explored in this research are the biophysical processes that cause pluvial flooding, the role of participatory flooding reports, and social vulnerability within stormwater system and flood risk planning. While previous studies have examined each of these frameworks individually regarding urban flood risk, few studies have combined these three frameworks to examine pluvial flood risk at a city scale.

The first chapter of this study will explore the biophysical processes that cause pluvial flooding by associating citizen-observed flooding reports with 3-day storm sizes to understand the relationship between storm size and frequency of reports. The first chapter will also explain the categorization, standardization and overall data processing of citizen-generated flood reports. The second chapter of this study will explore the validity and usefulness of citizen-inputted flood data for evaluating flood risk by examining the relationship of reports with both a predictive surface flood model based on topography, and with socio-demographic and building characteristics at the census tract scale. While the first chapter will explain some of the caveats with collecting and processing citizen-inputted data, the second chapter will explore some potential issues surrounding equity of using citizen-inputted data within city-wide flood risk planning. Thus, this research uniquely examines the full cycle of how participatory flooding data gets recorded and analyzed within urban flood risk and stormwater system planning. 


\section{Research Objective and Questions}

The objective of this research is to examine the spatial characteristics and frequency of citizen-observed flooding reports from 2010-2017 in Portland, OR, as well as the validity of using participatory data to evaluate urban flood risk. This research aims to explore how future stormwater management and flood risk planning can better address the physical and social dimensions of flood vulnerability through biophysical processes and socioeconomic characteristics that exists among communities in Portland. This research aims to address the following questions:

1. What are the spatial patterns of flooding reports at different periods of the wet season?

2. Does storm size influence the frequency of reports generated?

3. Are reports spatially correlated with known topographic characteristics that cause surface flooding?

4. What are the building and socio-demographic characteristics associated with flooding reports? 


\section{Chapter 1}

\section{Introduction}

Weather-related hazards are expected to occur more frequently as climate change projections anticipate uncertainty in precipitation patterns that could vary spatially and temporally at local and regional scales (Chang \& Franczyk 2008). As climatic uncertainty increases, the ability for urban systems to predict and cope with weather-related hazards becomes increasingly pertinent to understand. One of the more common weather-related hazards within urban systems is pluvial flooding, which is most often associated with rapid urbanization, increased population, installation of varied infrastructure and changes in precipitation patterns (Jenkins et al. 2017). While this type of flooding does not pose serious threats to human life or infrastructure, it occurs frequently and disrupts daily activities, increases traffic congestion, strains sewer systems and causes property damage (Moftakhari et al. 2018).

Previous studies have examined different measurements of precipitation associated with flooding events (annual maximum, 3-day total, daily, hourly and one-minute rainfall) to understand how rainfall intensity will affect the occurrence of flooding events (Guerreiro et al. 2017, Hailegeorgis \& Alfredsen 2017, Ye et al. 2017). Since pluvial flooding is most often caused by intense, localized storm events that could take several days to develop, it is important to understand storm sizes over a 3-day period (Guerreiro et al. 2017, Ye et al. 2017). It should 
be acknowledged that strong winter storm events in the Pacific Northwest (PNW) that induce flooding events are often caused by Atmospheric Rivers (ARs) which contain large amounts of water vapor and are responsible for more than $90 \%$ of atmospheric water vapor transport in the mid-latitudes (Ralph \& Dettinger 2010).

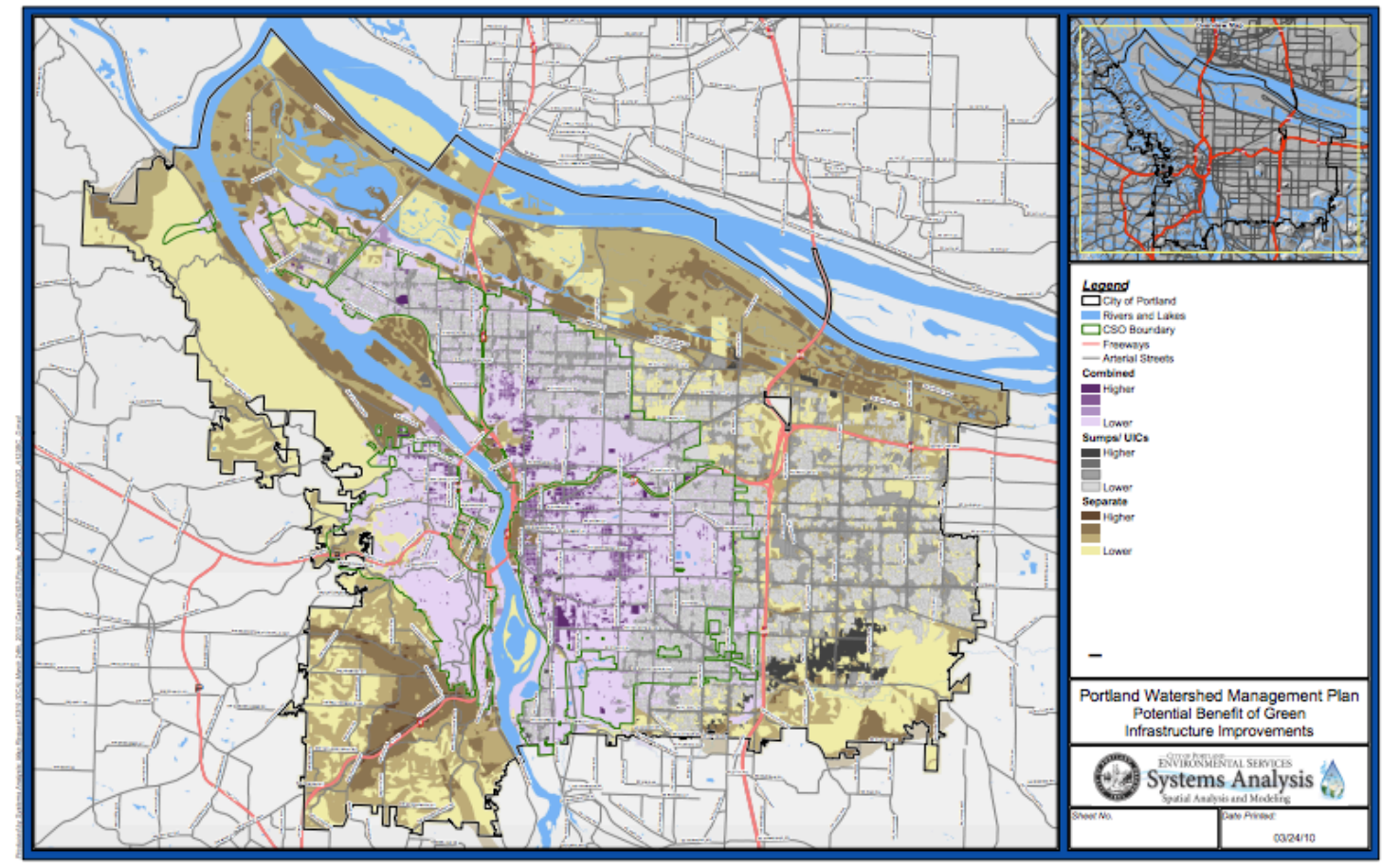

Figure 1: Map of the three sewer systems across Portland. Purple indicates the combined sewer system, grey is the Sumps/UICs, and the yellow to brown tones are the separate sewer system regions (City of Portland 2010).

The city of Portland has the largest wastewater collection system in Oregon and serves over 588,000 customers, spanning more than 94,000 acres in service area (City of Portland 2010). The city manages stormwater in three distinct systems: combined sewer system (CSS), underground injection control 
(UIC) and separate (i.e. sanitary) storm sewer (SSS) system. As shown in Figure 1, CSSs are predominantly located in central regions of the city near the Willamette River and collect stormwater runoff and sewage from streets and buildings into the same pipes. While most of this stormwater is routed towards treatment plants in the city, heavy rainfall can cause combined sewer overflows (CSO) to the Willamette. The city completed its CSO control system in 2011 to alleviate a majority of the sewage overflows to the Willamette when it rains (City of Portland 2010). UICs (i.e. sumps), located in the northeast and eastern regions of the city where the ground is more permeable, route stormwater runoff to the ground, and replenish groundwater to feed rivers and streams (City of Portland 2010). SSS systems, mostly located in the outer regions of the city, route sewage from buildings to treatment plants, and collect stormwater runoff through stormwater conveyances such as pipes, drainages, and swales (City of Portland 2010).

While Portland has a fairly advanced and efficient stormwater management system in place, localized pluvial flooding still occurs across the system, and there is a lack of certainty in the spatial location of these events. City stormwater engineers have been able to create predictive models of basement sewer backups, surcharged manholes and sanitary sewer overflows (SSO), but have not been able to validate these models with reports of where flooding actually occurs across the system. Previous studies have explored the usefulness of participatory spatial data to validate predictive modeling of flood 
risk as citizens who report flooding incorporate local knowledge, personal experiences and more relevant georeferenced information (Fazeli et al. 2015, Hung et al. 2016, Klonner et al. 2016, Sing 2014). For these reasons, this study will use a dataset of mostly citizen-observed flooding reports to understand the spatial distribution of pluvial flooding across Portland in order to compare results to predictive surface modeling of flooding.

\section{Study Area}

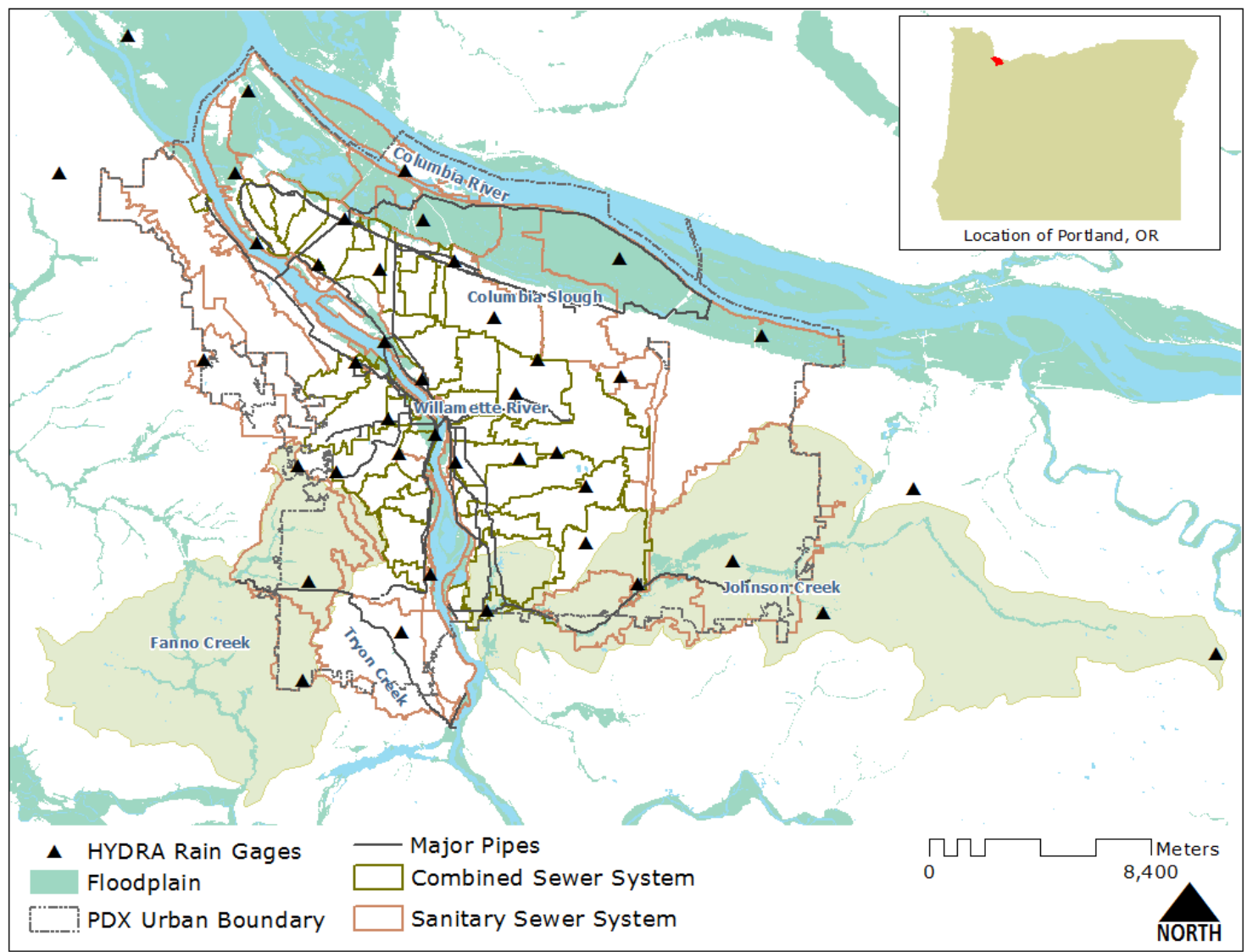

Figure 2: Study area map of Portland, OR 
The center of Portland, OR. is located at 45.51 degrees north latitude and 122.66 degrees west longitude in the Pacific Northwest (PNW). Portland is located in the mid-latitudes within the Willamette Valley, bordered by the Coast Range and Cascade Range. The Coast Range provides partial shielding from the Pacific Ocean, and the Cascade Range causes orographic uplift from westerly winds, which results in moderate rainfall throughout the Willamette valley during fall, winter, and spring months. Portland experiences relatively little precipitation in comparison to other regions of the PNW, yet still receives approximately 92.96 $\mathrm{cm}$ (36.6 in) of rain annually with about $61.98 \mathrm{~cm}(24.4$ in) occurring between November and April (based on 1981-2010 climate normals) (Chang 2007, Cooley \& Chang 2017). The beginning of the wet season (October-December) on average receives approximately $38.1 \mathrm{~cm}$ (15 in) of rain, the middle (JanuaryFebruary) receives approximately $25.4 \mathrm{~cm}$ (10 in), and the end of the wet season (March-April) receives approximately $15.24 \mathrm{~cm}$ (6 in) of rain (Daly et al. 1994).

The city contains two urban watersheds, Johnson Creek and Fanno Creek, and both watersheds possess high flooding potential due to their flashy and mostly high streamflow during wet periods of winter (Chang et al. 2010). The topography of Portland is much steeper further west of the city as residential homes are backed up to hills, while the east side has a much flatter terrain. Additionally, soil on the west side of the city is mostly clay while soil on the east side is more permeable and allows for more water infiltration (City of Portland 
2015). These differences in elevation, slope and soil characteristics contribute to where pluvial flooding occurs across the landscape.

\section{Methods}

\subsection{Data Collection and Processing}

As a collaborative effort with the City of Portland, Bureau of Environmental Services (BES), mostly citizen-observed flooding reports $(n=9804)$ were flagged from six different categories in the City's TrackIT database, which a database managed by the Portland Bureau of Transportation to log customer calls about sewer and stormwater related problems (Table 1). While a majority of reports were made by citizens, the TrackIT database could also contain reports made by city practitioners, although this was a seldom occurrence. The six categories examined were as follows: sewer cleaning, sewage release, sewer repair, plugged inlets, stormwater, and slide.

Table 1: Categorization of citizen-observed flooding reports in City TrackIT database

\begin{tabular}{|l|rrrrrrrr|}
\hline $\begin{array}{l}\text { TrackIT } \\
\text { Categories }\end{array}$ & \multicolumn{70}{|c|}{ Potential Causes of Flooding Reports } \\
\hline & Capacity & Maintenance & \multicolumn{1}{l|}{ Maintenance or $\begin{array}{l}\text { No } \\
\text { Capacity }\end{array}$} & $\begin{array}{l}\text { Others } \\
\text { System }\end{array}$ & $\begin{array}{l}\text { Poor } \\
\text { Design }\end{array}$ & Total \\
\hline $\begin{array}{l}\text { Plugged } \\
\text { Inlets }\end{array}$ & 168 & 6004 & 199 & 12 & 56 & 66 & 6505 \\
\hline $\begin{array}{l}\text { Sewage } \\
\text { Release }\end{array}$ & 60 & 865 & 660 & 1 & 11 & 10 & 1607 \\
\hline $\begin{array}{l}\text { Sewer } \\
\text { Cleaning }\end{array}$ & 77 & 1081 & 80 & 3 & 136 & 10 & 1387 \\
\hline
\end{tabular}




\begin{tabular}{|l|rrrrrrr|}
\hline $\begin{array}{l}\text { Sewer } \\
\text { Repair }\end{array}$ & 1 & 8 & & & 1 & 1 & 11 \\
\hline Slide & 3 & 4 & 10 & 1 & 68 & & 86 \\
\hline Stormwater & 8 & 138 & 10 & 10 & 20 & 22 & 208 \\
\hline Total & 317 & 8100 & 959 & 27 & 292 & 109 & 9804 \\
\hline
\end{tabular}

While these six categories were identified as portraying potential flooding reports by BES, extensive data processing was required to specifically flag flooding reports within these six distinct categories. Each report contained the following fields to help decipher flooding potential: location, date and time, description and comment fields. A description of the flooding report was conveyed to a city practitioner by the citizen through a telephone or web-based platform. A comment field was then inputted by a city employee who went into the field and inspected the location and issue reported. Reports were evaluated for flooding based on a review of the description and comment fields, and an association with precipitation data.

The review of flooding reports initially started with grouping reports into six different categories to help city stormwater managers understand what potentially caused the flooding issue. These six potential causes of flooding were identified by city stormwater managers as the following: Capacity, Maintenance, Maintenance or Capacity, No system, Others, or Poor System. After grouping reports into potential causes, a more in-depth review consisted of scanning for keywords between the description and comment fields that indicated flooding, such as: basement sewer backup, overloaded system, plugged control basin 
(PCB), sewage backup/release, surcharged manhole, street flooding etc.

Additionally, the description and comment fields were cross-referenced to check for consistency between the citizen's observation of the flooding issue, and an actual inspection of the potential flooding issue by a city practitioner.

Reports categorized as flooding issues were often induced by surcharged manholes, PCBs and basement sewer backups. Reports that were categorized as non-flooding issues were often related to broken pipes, potholes, sinkholes, etc. Since mostly citizens submitted reports to TrackIT, locations and other details of flooding reports might not be completely accurate. For example, a report might be associated with the address of the reporting party, rather than the flooding location itself. Additionally, report descriptions and comments were not always clearly articulated or complete, thus it was challenging at times to decipher the true issue being reported. Regardless, the review of flooding reports relied on using best judgement with the information provided.

\subsection{Correlating citizen-observed flooding reports with storm events}

Precipitation data were obtained from the City of Portland, HYDRA rainfall network from 2010-2017. This study used 39 gages across the city which record rainfall at a resolution of 5-minute intervals per day (see Appendix). Rainfall data pertaining to each gage was associated with flooding reports using Thiessen polygons (ArcMap 10.5.1, see Figure 3). Thiessen polygons, an interpolation method that is commonly used for precipitation, were used based on traditional methods of computing mean areal precipitation over basins (Fiedler 2003). 5- 
minute rainfall intervals were summed to a 24-hour time-frame and used to compute prior 3-day storm sizes.

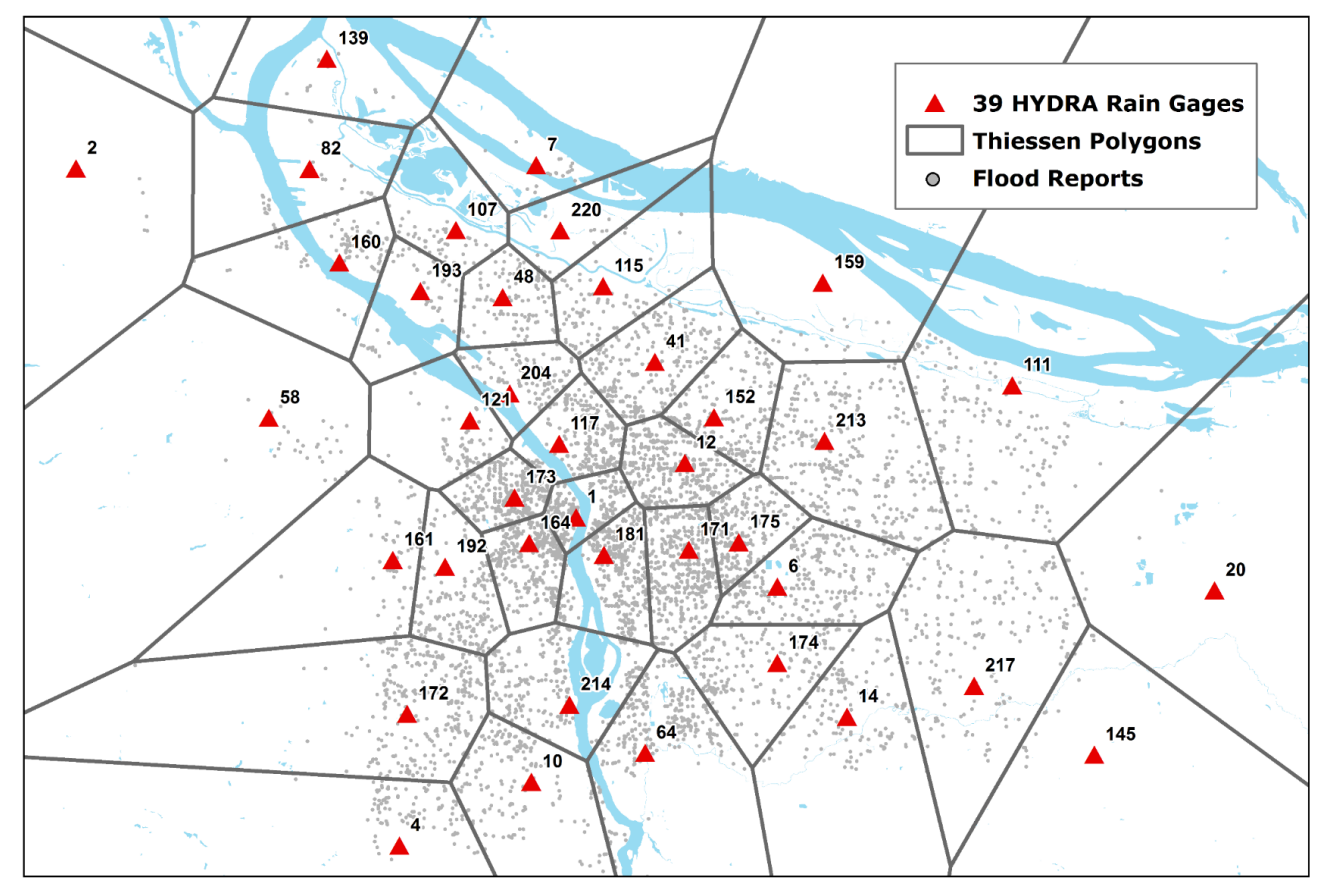

Figure 3: Methodology of associating HYDRA rain gages with flood reports based on Thiessen polygons

This study chose to associate flooding reports with 3-day storm sizes to be consistent with similar studies that have examined storm events associated with pluvial flooding, and the influence of Atmospheric Rivers that are responsible for a majority of winter storm events in the PNW (Guerreiro et al. 2017, Ralph \& Dettinger 2010, Ye et al. 2017). This method accounts for larger storm sizes that could take 3 days to develop, and the potential subjectivity of the actual date a citizen makes a flooding complaint. It should be noted that 3-day storm sizes are 
the rain accumulation of 2 days prior to the report date and the report date's rainfall volume. Days and times when a gage was malfunctioning were compared against report dates and times to see if a gage was down before, after, or during the report date. If a gage was down 72 hours prior to the report date, the report was associated with the nearest neighboring gage and the rainfall amount for that gage. This occurrence was rare and occurred less than $.01 \%$ of the time.

To understand the frequency of reports per storm size, we first examined the raw number of reports generated at 3-day storm sizes. In order to remove bias of the high frequency of reports generated at smaller storm sizes, we normalized reports across gages and days to account for the effect of less frequent or larger storm sizes. This normalization took a ratio of the total number of reports per rain interval over the total number of calendar days that received the different intervals of rain, which is a more accurate representation of reports generated at different 3-day storm sizes.

\subsection{Spatial distribution of flooding reports}

Flooding reports were divided into three distinct periods of the wet season to account for differences in precipitation totals that occur across the PNW; beginning (October-December), middle (January-February), and end (MarchApril). As previously stated, the beginning of the wet season receives the most rainfall out of the three time periods, thus we would expect to see more flooding reports generated in the beginning of the wet season (Daly et al. 1994). Late spring and summer months (May-September) were grouped together to account 
for drier and warmer months that rely more heavily on runoff from snowmelt to feed rivers and streams than precipitation (Oregon Institute for Water and Watersheds 2012).

In order to analyze the spatial distribution of flooding reports across different periods of the wet season, a map of report density was generated. The kernel density method in GIS was used to create a smooth curved surface over all fitted points (Anderson 2009). The algorithm of a kernel density analysis relies on a specific cell size and search radius to determine the weighted distance between points. To be consistent with similar analyses completed by BES GIS practitioners, a cell size of 3 feet and a search radius of 1000 feet were used in the calculation for each of the four maps generated. Maps were then symbolized using the percent-clip stretch option in ArcMap which removes a percentage of the highest and lowest values to reduce the influence of outliers in the dataset (ESRI 2017).

\section{Results}

\subsection{Frequency of flooding reports per 3-day storm size}

Figure 4a indicates the raw number of reports produced at three-day storm sizes with a range $0.25-15.49 \mathrm{~cm}(0.10-6.10 \mathrm{in})$ of rainfall over the observed time-period. The figure indicates that a majority of flooding reports were generated after $5 \mathrm{~cm}$ (2 in) or less of rainfall within a 3-day period while fewer reports were generated at larger storm sizes. Figure $\mathbf{4 b}$ indicates the 
normalization of reports generated per storm size across all days and rain gages to account for the effect of less frequent or larger storm events. This graph indicates that although larger storm events did not occur as frequently over the observed time period, there was still a high number of reports generated at larger storm sizes of $10-15 \mathrm{~cm}(4-6 \mathrm{in})$. 


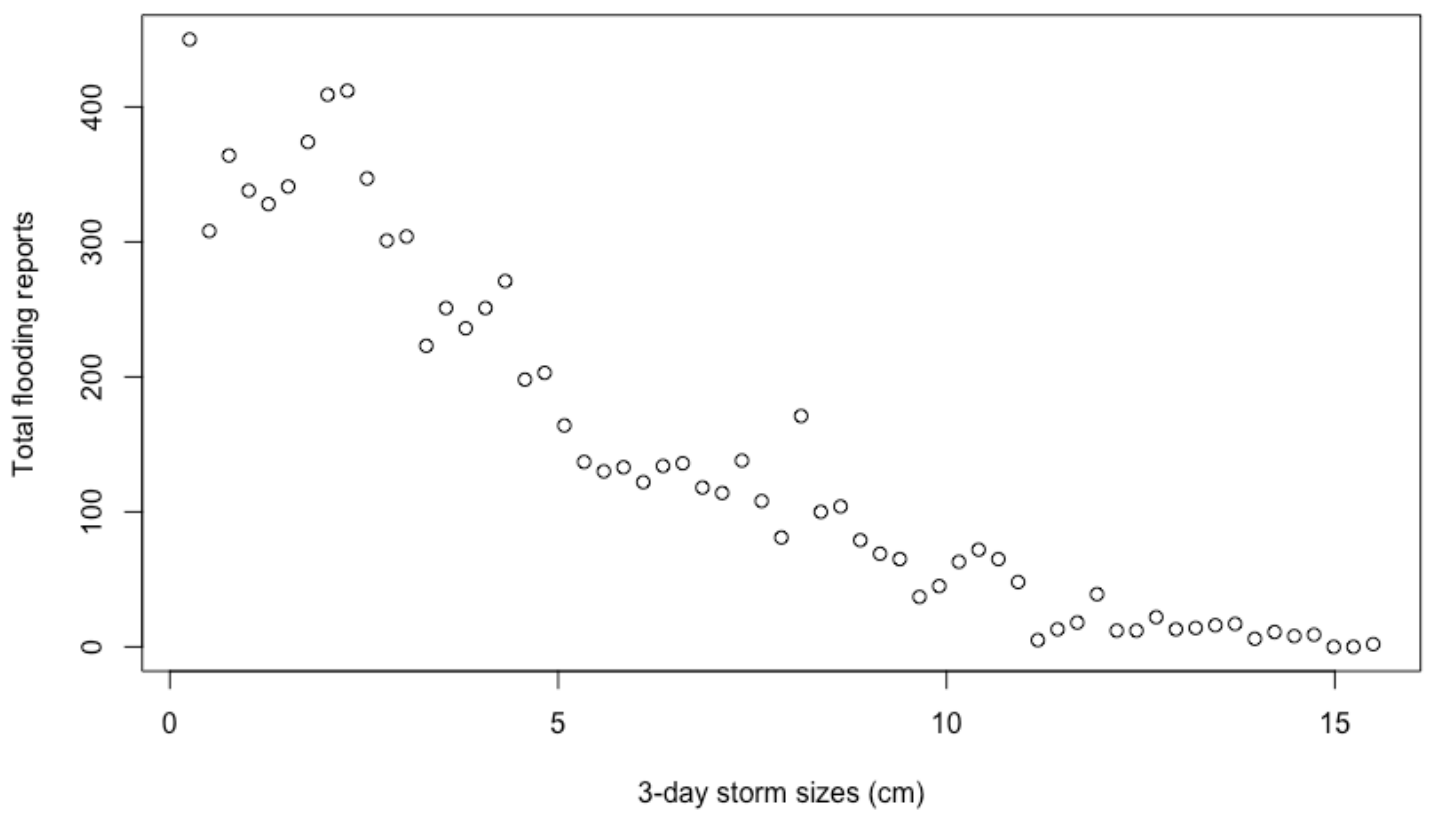

(a)

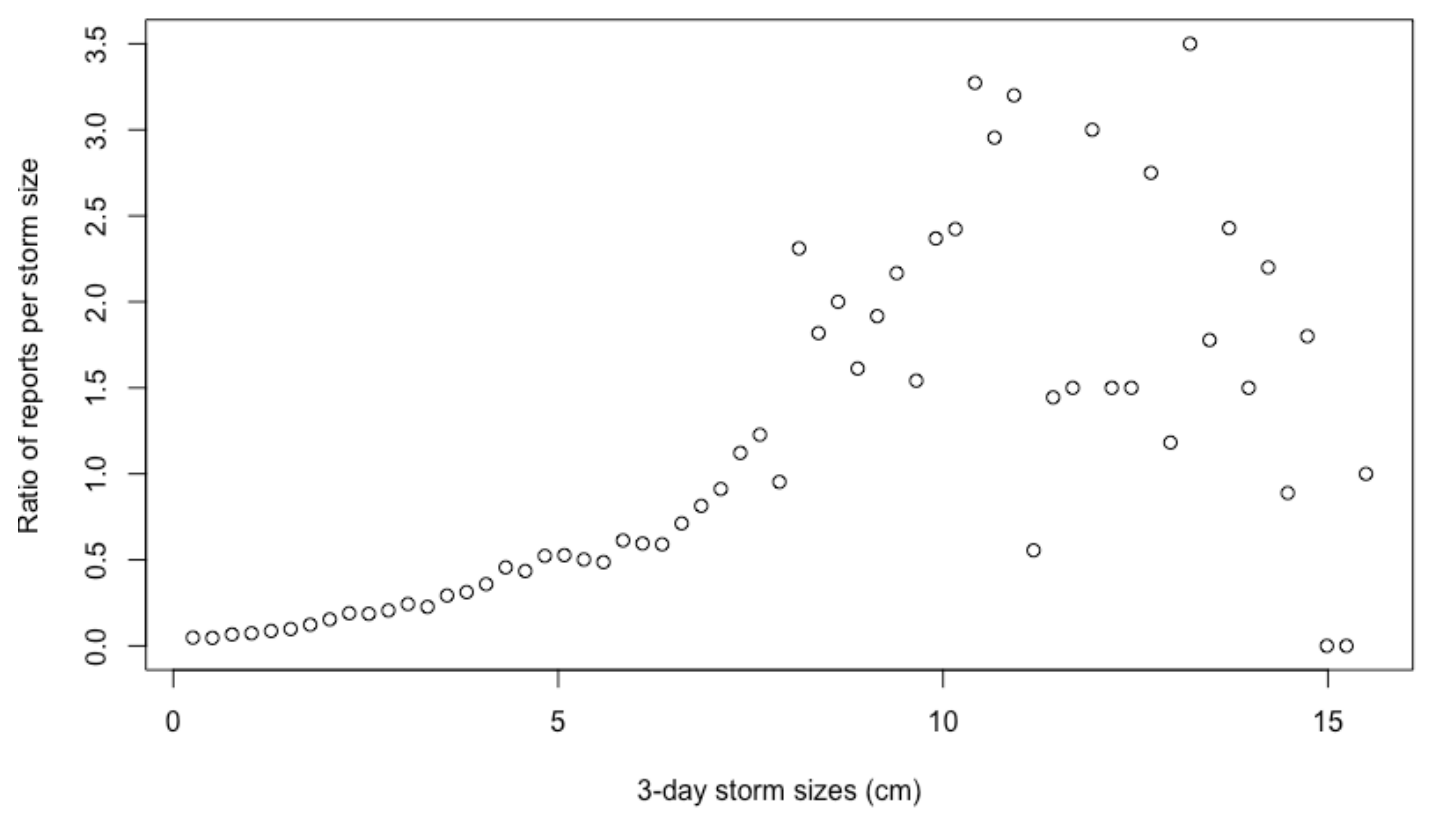

(b)

Figure 4: a) total flooding reports ( $\mathrm{n}=9804)$ from 2010-2017 at different 3-day storm sizes $(\mathrm{cm})$, b.) Ratio of flooding reports over the total calendar days per 3-day storm size $(\mathrm{cm})$ 
4.2 Spatial analysis of flooding reports by different periods of the wet season

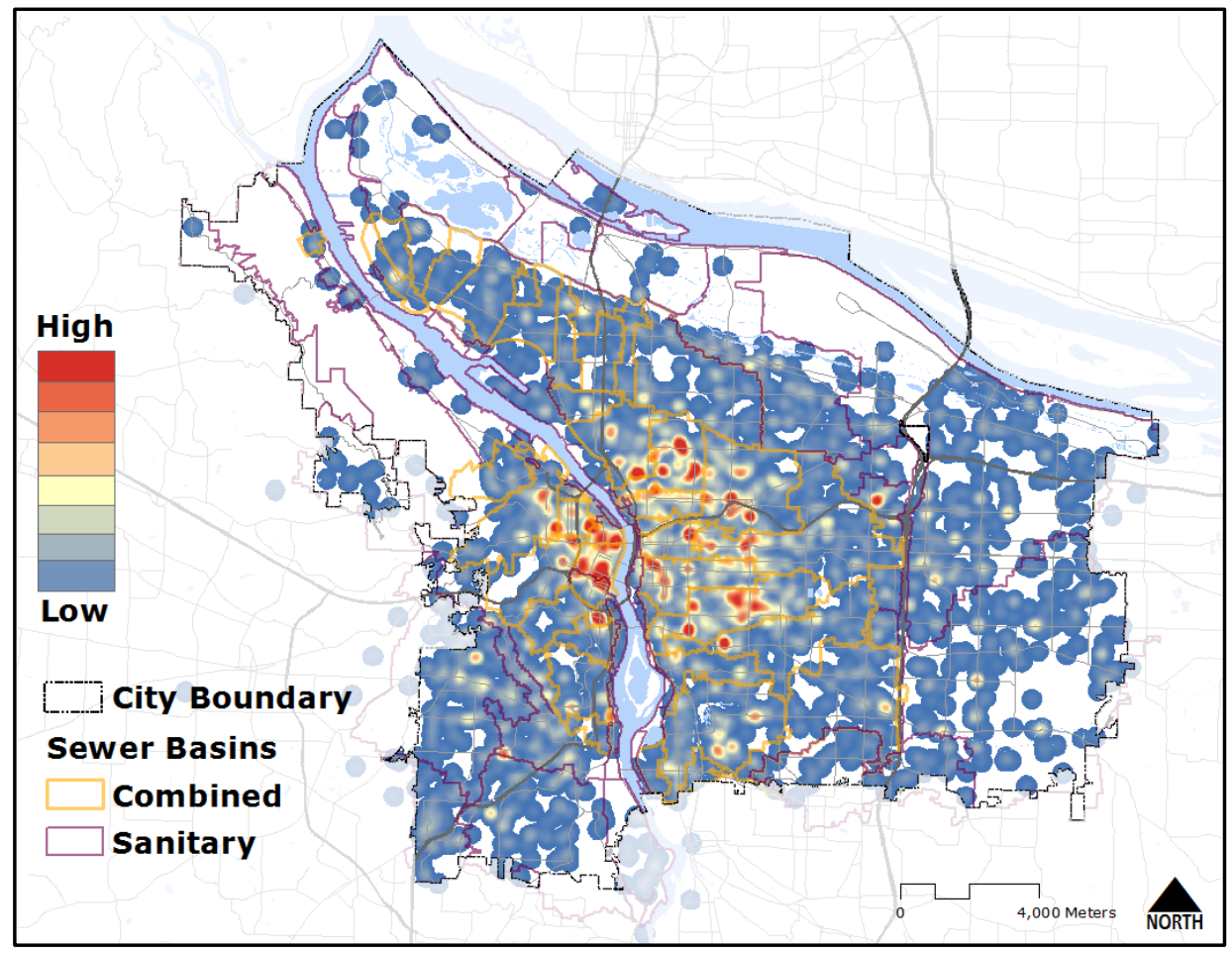

(5a) 


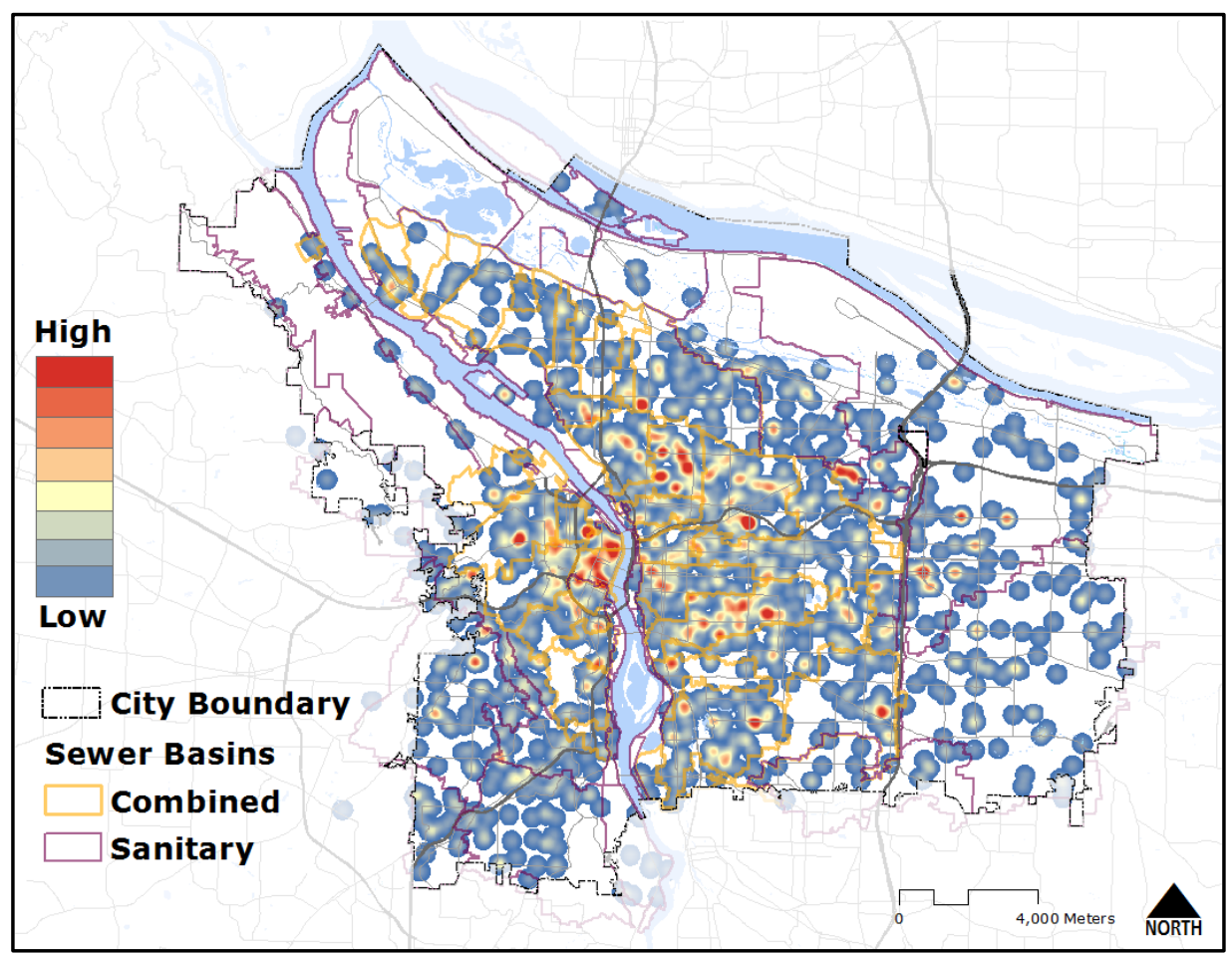

(5b)

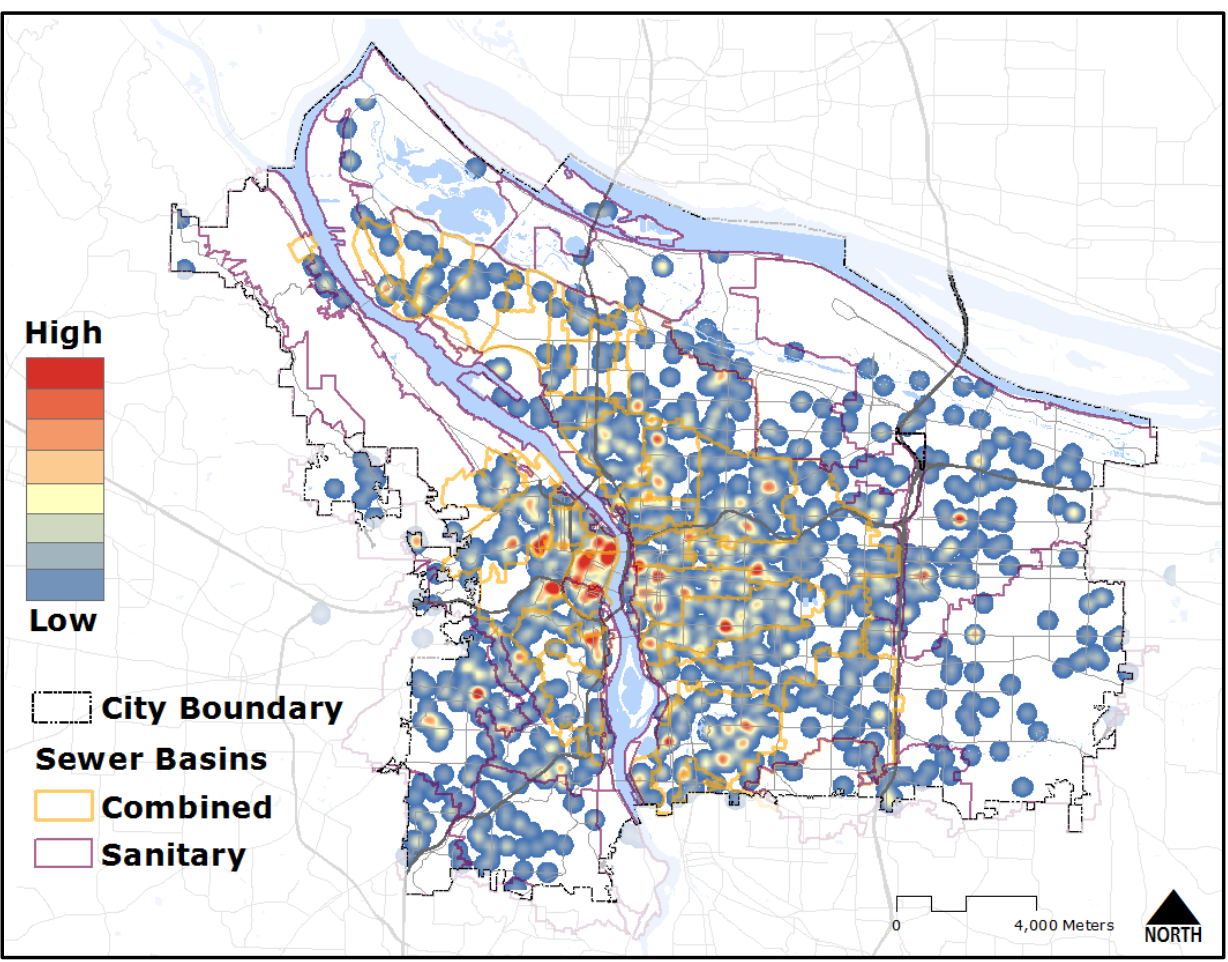

(5c) 


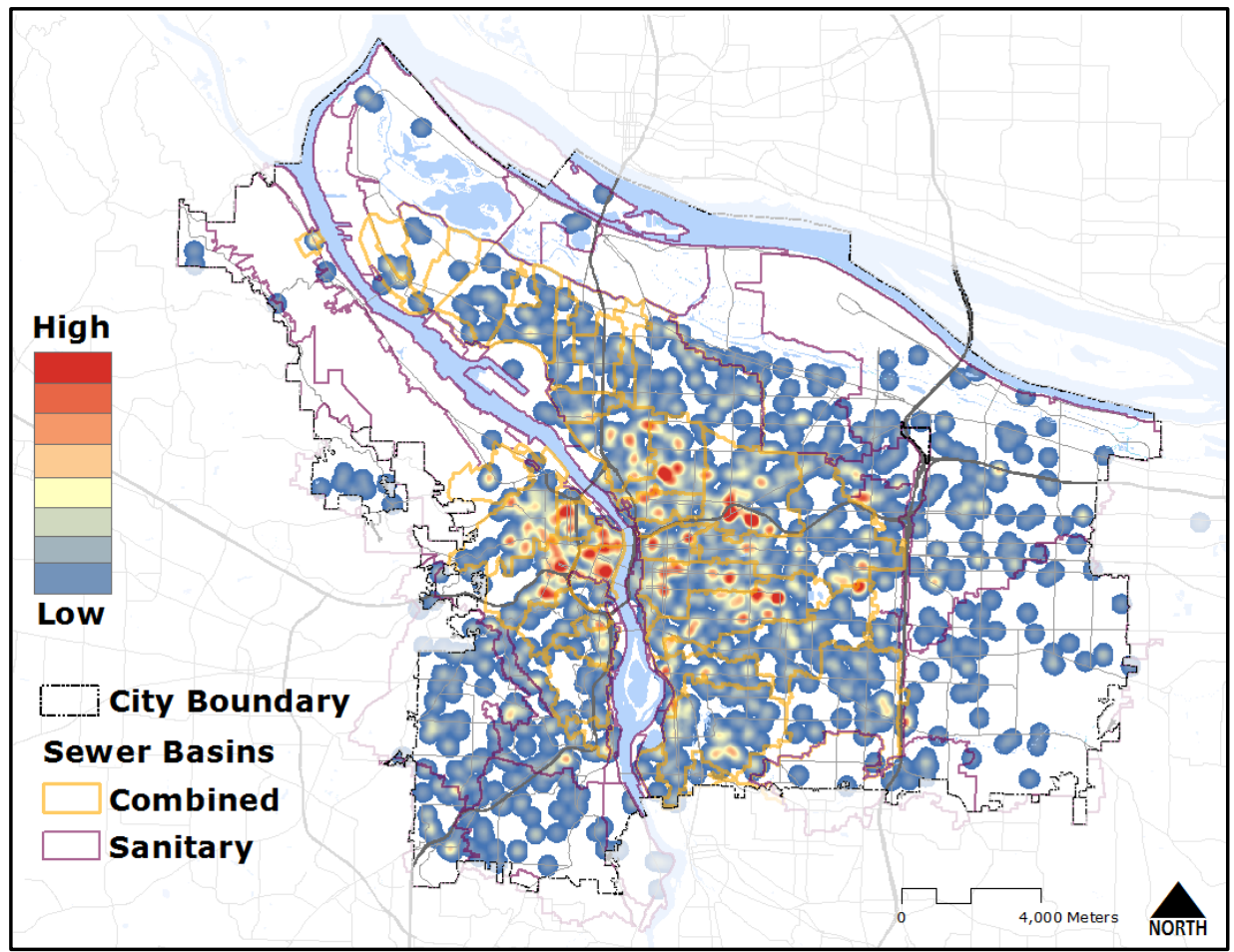

(5d)

Figure 5: Maps of the density of reported flooding from 2010-2017. a) Oct-Dec. reports. b) Jan.-Feb. reports. c) March-April reports. d.) May-Sept. reports

The results shown in Figure 5a-d displays the spatial distribution of reports generated by indicating high to low density of reports across the city. The highest density of reports is indicated in red, while the lowest density of reports is indicated in blue. It should be acknowledged that legends are not standardized across the four maps, thus relative density is being shown as opposed to equal density. Overall, results from the four maps proved to be consistent with the assumption that most reports were generated in the beginning of the wet season, with the least number of reports generated during the late spring and summer months. Most reports were also clustered within the combined sewer system with 
only a few regions of high clustering within the sanitary sewer system. The beginning of wet season is comprised of three months (Oct.-Dec.) while the middle and end of the wet season are comprised of only two months; therefore it is important to understand these results by normalizing reports per month, which maps do not indicate this normalization.

In examining the spatial patterns of flooding reports over different periods of the wet season, there were only slight differences in spatial clustering of reports. In looking at the spatial distribution of reports (approximately 1655 reports per month) generated in the beginning of the wet season in Figure $\mathbf{5 a}$, there was high clustering of observed flooding reports in the central regions of the city near the Willamette. Most of the high clustering appears to be within the central NW region and in the central eastside and SE neighborhoods. Figure $\mathbf{5 b}$ shows the spatial distribution of reports (approximately 875 reports per month) generated in the middle of the wet season (Jan.-Feb.), which has a similar spatial pattern to the previous map, but reports are not as densely clustered in central downtown regions. This map also indicates high clustering of reports in the outer NE neighborhoods of the city.

The results from the end of the wet season (March-April) show far fewer reports generated during this time period as expected (approximately 706 reports per month) (Figure 5c). Regardless, a high density of reports remains clustered in the central downtown regions west of the Willamette, with some relatively high clustering in the central eastside districts. Lastly, the spatial distribution of reports 
generated during the drier months of late spring and summer (May-Sept.) show a similar pattern to the beginning of the wet season as most reports were clustered within the central west and east sides, as well as the SE regions of the city (approximately 336 reports per month) (Figure 5d).

\section{Discussion}

\subsection{Frequency of reports by storm size}

Results indicate that citizen-observed flooding reports were predominantly generated at smaller storm sizes (i.e. less than $5 \mathrm{~cm}$ of rainfall over a 3-day period) throughout the observed time period. One potential interpretation of this result is that smaller storms occur more frequently, thus we can expect the frequency of reports to be closely correlated with the frequency of storm events. Another interpretation is that citizens may not report flooding at larger storm sizes because they might assume the city is already aware of such flooding issues, hence reporting a flooding complaint on days with heavy precipitation would be repetitive, which is something that has not been previously discussed in supporting literature.

In normalizing reports across all days and rain gages to account for the effect of less frequent or more localized storm events, results indicated that while larger storms do not occur as frequently as smaller storm sizes, the rate at which citizens report larger storm sizes is still relatively high. For example, after 13.21 $\mathrm{cm}$ (5.2 in) of rainfall within a 3-day period, 14 flooding reports were generated 
even though only four calendar days received this much rainfall within the observed time period. This result counters previous assumptions that citizens do not report flooding at larger storm sizes due to city's knowledge of such events, and thus requires a further understanding of what provokes citizens to report flooding.

\subsection{Spatial distribution of flooding reports}

Overall, we found a similar clustering of reports within the central regions of the city regardless of the amount of precipitation received during the year. Across the beginning, middle and end of the wet season, as well as the drier early spring and summer months, we found the density of reports mainly clustered around the NW downtown and central eastside regions of the city. This high density of reports could be because these are the most densely populated regions of the city for residents and businesses. These regions also receive heavy foot traffic and congestion from commuters passing through downtown since these are the main business and commercial districts of the city. Another potential interpretation of these results could be based on the topography of the west side which has a steeper terrain than the east side. Since a majority of westside residential homes are backed up to the SW hills, these homes experience surface flooding from rainfall making its way downhill onto taxlots. Thus, we can interpret the high density of reports in central regions of the city to be related to population density and varying topography in Portland. 
We also infer that most reports were clustered downtown due to differences in pipe size upstream versus downstream of the Willamette. The smaller diameter upstream collection pipes can convey the flow downstream, but the downstream collection system becomes overwhelmed with the accumulated flow from upstream. Additionally, larger storm sizes 5.08-15.24 cm (2-6 in.) can overwhelm the smaller diameter pipes upstream, and therefore flow is not able to make it downstream. This may be why a majority of reports were clustered downstream near the Willamette since most reports were generated at smaller storm events.

Most reports were generated within the CSS, indicating that periods of heavy rainfall might have caused pipes to exceed capacity. These regions are more subject to basement sewer backups and surcharged manholes because when stormwater does not make its way into the CSS, sewers reach capacity, which does not allow for sewage water to mix with stormwater, leading to sewage overflows from pipes. However in looking at the potential causes of flooding reports in Table 1, we found most flooding reports categorized as maintenance issues with the most common keyword and issue amongst all six categories to be from plugged catch basins (PCB). Since PCBs are most often caused by debris buildup (i.e. cement, dry dirt, mud, etc.) or fallen leaves from deciduous trees, it is possible that a majority of flooding reports were not from capacity issues in the CSO system, but clogged inlets from building debris or fallen leaves. Since the location of flooding reports are within the central regions of the city where new 
buildings projects (i.e. high-rises and condominiums) are being constructed, it is possible that plugged inlets were caused by building debris. Additionally,

downtown and other regions with a high number of flood reports have a large number of street trees, in which $92 \%$ of street trees in Portland are broadleaf deciduous trees that lose their leaves during the fall and winter months (DiSalvo et al. 2017). Thus it is likely that flooding reports within the beginning of the wet season were also caused by plugged inlets from fallen leaves.

Another possible interpretation of reports being clustered in central regions of the city could be attributed to citizens on the east side being more accustomed to localized flooding from UICs. UICs were built before the CSS and are therefore much older and cannot keep up with the level of construction occurring on the eastside. Since UICs have been functioning for over 60 years, they have degraded over time and need to be renovated, but have not seen the same level of renovation as the CSS which was updated in 2011 to control CSOs to the Willamette (City of Portland 2010, 2015). Therefore, surface flooding should occur frequently on the outer eastside, but the dataset is not representative of reported flooding in these regions.

\section{Conclusions}

The objective of this part of the research was to examine the spatial distribution and frequency of citizen-observed flooding reports from 2010-2017. 
Furthermore, this part of the study aimed to address if the frequency of reports was associated with specific storm sizes, and if the spatial distribution of reports was similar or different depending on the time of the wet season in the PNW. Results from this analysis suggests that the highest frequency of flood reports were associated with smaller storm sizes (i.e. $5 \mathrm{~cm}$ or less) since smaller storm events occurred most often during the observed time period. Although, results from this analysis found that citizens do report flooding induced by larger storm sizes at a relatively high frequency, but larger storm events do not occur as often. Results also indicated that reports were mainly clustered in central regions of the city regardless of the time of year the reports were generated. Since the central NW and eastside regions of the city is where a majority of residents and commercial businesses exist, as well as where many new construction projects are occurring, this result could be indicative of population density within these regions.

While these results are helpful in determining where localized pluvial flooding occurs across the city, there are still major caveats in using participatory spatial data that should be acknowledged. Previous studies have explored the inherent issues of credibility and reliability in using participatory spatial data for mapping urban flood risk in terms of quality assurance and quality control of the data (Fazeli et al. 2015, Hung et al. 2016, Singh 2014, Uson et al. 2016). Regardless of the results indicated by this analysis, it is important to acknowledge the difficulties with categorizing and standardizing citizen-observed 
data. While the review and flagging of flood reports was based on recommendations from BES stormwater engineers, there are still potential uncertainties introduced in this approach due to unavoidable human error in the translation and review process of reports.

Since the description of the report relies on the citizen's own knowledge of the infrastructure that experienced flooding, the citizen could be inaccurately describing a flooding issue by not using the proper terminology. While the address of the flooding complaint is recorded by a city practitioner, it is possible the citizen reporting the issue could be giving their home address while the flooding occurred in the intersection near their home or where they work. Consequently, the comment field inputted by the city practitioner could be misinterpreted due to receiving an inaccurate location of where flooding was observed. Lastly, cross-referencing between the description and comment fields in flagging flooding reports introduces potential biases because this process is solely reliant on an analyst's perception and best judgement with the information provided.

A potential recommendation for city stormwater managers using participatory data to assess the spatial location of pluvial flooding is to create a flood specific category within the city tracking database. By having a separate category for flood reports, the data collection becomes more streamlined and less subjective, as uncertainties associated with searching for flood reports within different potential flooding categories is removed. Another recommendation is 
limiting citizens to only selected keywords (i.e. PCB, surcharged manhole, etc.) that describe the potential cause of flooding, as this would make the process of standardizing and categorizing reports much more efficient. If citizens are not certain of the potential cause of flooding, city practitioners would have to use their best judgement in extracting information from the citizen that fits only within the selected keywords. It is also important for city practitioners to make sure the citizen is giving the correct address or intersection of the flooding issue to not introduce potential biases in the spatial location of the point of flooding. These improvements would help city managers better understand where they need to either prioritize and build new stormwater infrastructure, or where they need more maintenance staff attending to plugged storm drain inlets.

Furthermore, while the city TrackIT database has an online and phoneapplication platform that citizens can access to report flooding issues, almost all flood reports were from telephone calls. This could be due to issues with usability and accessibility of the online platforms that need to be improved. Since most organizations have transitioned to using online platforms to convey and track information, and as citizens have become more accustomed to using these online platforms, we need to take advantage of this technology for tracking natural hazards, which previous literature has alluded to (Xu \& Nyerges 2017). One possible suggestion would be the development of a mobile application that allows users to directly place the point of flooding on a map, and answer a series of questions that allow only certain options as a response. This would alleviate 
open-ended descriptions of reports, and allow for a more standardized approach. If citizens were able to adequately access and use mobile applications to report flooding, we believe issues with translating flood reports to city practitioners could be lessened. 


\section{Chapter 2}

\section{Introduction}

Understanding where pluvial flooding occurs spatially across an urban system is not a simple task for city agencies to monitor (Rosenzweig et al. 2018). While city and government agencies are often able to create predictive flood models based on historical flooding data, they are usually not able to compare these models to a ground-truth perspective of where flooding realistically occurs within an urban system. For this reason, it is important to understand the relationship between predictive flood models and actual flooding data, which can be best understood by individuals on the ground who experience flooding issues (Fazeli et al. 2015, Singh 2014). By comparing predictive models based on topographic characteristics of an urban system with citizen-observed data, we are able to gain a better sense if the models are accurately predicting where flooding predominantly occurs, and consequently, are giving citizens a participatory role in flood management practices and planning.

While participatory spatial data can help validate predictive models of flooding, there are inherent issues of credibility and reliability of the dataset itself, since the data is not necessarily spatially comprehensive and is only representative of those who participate (Fazeli et al. 2015). Previous studies have used in-depth and semi-structured surveys and interviews to understand the perspective of residents who experienced natural hazards (Singh 2014, Uson 
et al. 2016). Specifically, a study by the Johnson Creek Watershed Council (JCWC), which is a voluntary watershed council in the Portland area, found through conducting surveys and semi-structured interviews of residents on the council, that the council over-represented the interests of residents of high socioeconomic status, and under-represented residents of predominantly lower socioeconomic status (Larson \& Lach 2010).

According to Wisner (2004), social vulnerability stems from certain populations having a disproportionately lower capacity to anticipate, cope with, resist, and recover from the impact of a natural hazard (11). Previous research examined social vulnerability to flooding in relating to the core concepts of adaptive capacity, sensitivity and exposure (Douglas et al. 2012, Elliot \& Pais 2006, Romero-Lankao et al. 2014). These studies focused on the ability of lowincome and minority communities to respond to and cope with natural hazards before and after they occur, and the need for prior knowledge, resources, and adaptation strategies in place for communities to be resilient.

In addressing the level of preparedness before a natural hazard occurs, previous research has shown that low-income and minority communities are not provided with the necessary knowledge of the natural hazard directly impacting their local community, or the potential impacts of climate change that could worsen these impacts over time (Douglas et al. 2012). This lack of awareness stems from social and cultural obstacles that exist between agencies and communities at risk. Issues of trust and a common language that both parties can 
relate to and agree with, make it a challenge to convey more technical language related to risks and climate change impacts (Agyeman et al. 2002, Lynn 2017, Youngman 2009).

Previous studies have examined socio-demographic characteristics associated with high social vulnerability to natural hazards such as race, socioeconomic status, renter status, education level, gender and age (Bates 2012, Cutter \& Finch 2007, Denton 2002, Grineski et al. 2012, McKenzie 2013, Rasch 2017). While these characteristics are widely used in most social vulnerability indexes to examine the impact of natural hazards, the most common indicators of vulnerability to natural hazards are race and socio-economic status (Douglas et al. 2012, Elliot \& Pais 2006, Rasch 2017, Romero-Lankao et al. 2014). While previous research determined flooding to have a greater impact on marginalized communities since more affluent communities have more knowledge and access to resources to deal with flooding, there have been few studies that understand this correlation at a neighborhood scale through citizeninputted data (Douglas et al. 2011, Ge at el. 2017).

Previous studies have also examined the built environment associated with urban flood risk, as factors such as aging infrastructure and amount of impervious surface have been known to increase flood risk and vulnerability to flooding in urban environments (Jalayer et al. 2014, Jenkins et al. 2017, Koks et al. 2015, Krellenberg \& Welz 2017, Rothlisberger 2017). Understanding the relationship between the built environment and participatory flooding data have 
been used to understand coping capacity of communities of different socioeconomic backgrounds (Krellenberg \& Welz 2017).

\section{Study Area}

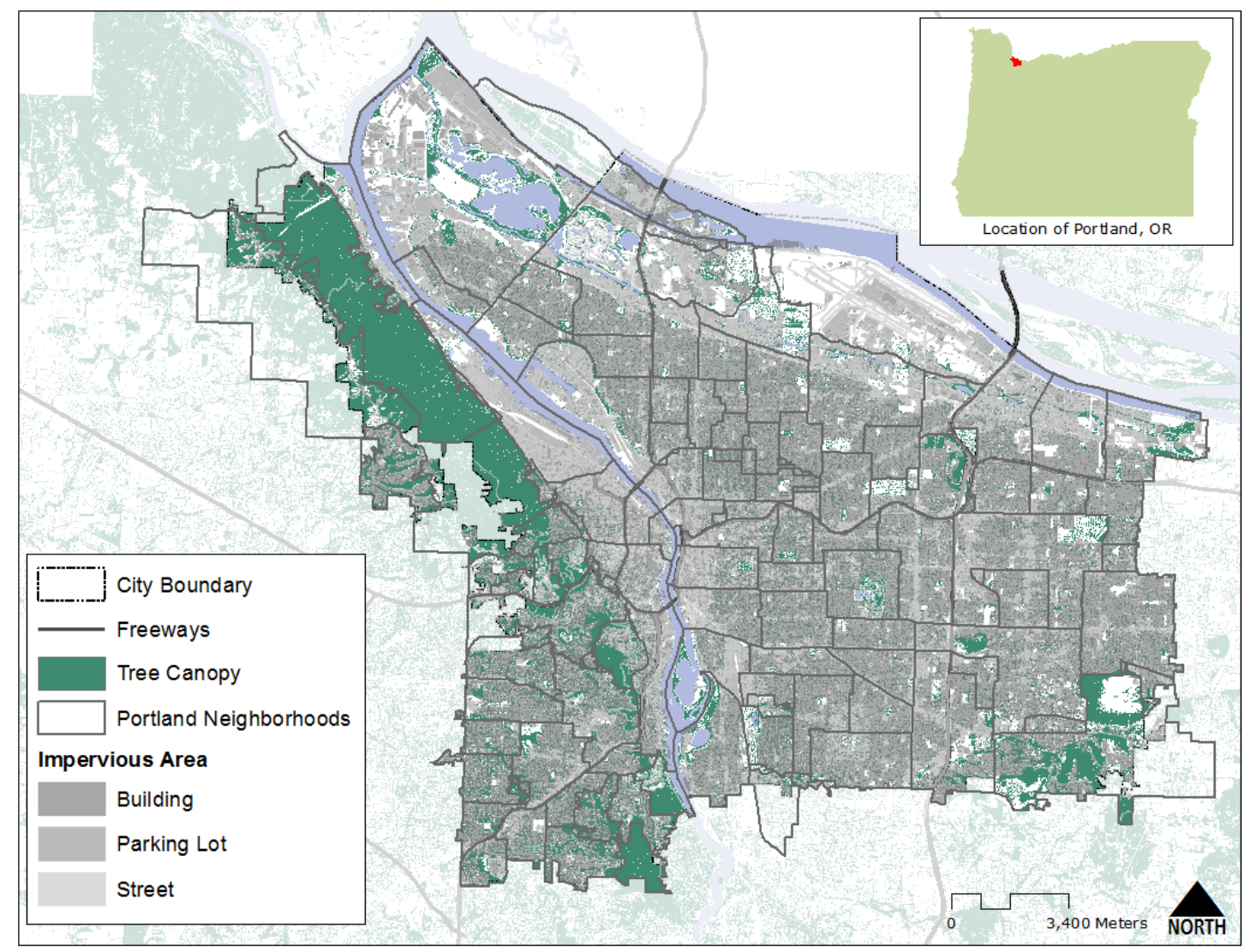

Figure 6: Study area map of Portland, Oregon

Figure 6 indicates the level of urbanization in Portland, OR. While the city prioritizes green space and street tree planting, more than half of Portland's land area is comprised of impervious surface (i.e. buildings, parking lots, and streets). Streets comprise of 25 percent impervious surfaces and rooftops comprise of 40 percent of impervious surfaces in Portland (City of Portland 2011). This makes 
stormwater management and stormwater green infrastructure (SGI) imperative because of the steady amount of precipitation Portland receives throughout most of the year.

The most populated and dense regions of the city are central downtown and east of the Willamette River, as this is where there is the greatest concentration of commercial businesses, and heavy foot-traffic from residents and tourists. Additionally, these regions have higher rental prices as newer condominiums are being constructed rapidly, and rental costs of older singlefamily residential homes are increasing due to the urban-growth boundary (UCB) that has encouraged density and infill development in Portland (Phillips \& Goodstein 2010).

\section{Methods}

\subsection{Summary of Data}

\subsubsection{Citizen-observed pluvial flooding reports}

Mostly citizen-observed flooding reports $(n=9804)$ were flagged from six different categories in the City of Portland's TrackIT database (see Table 2). See Chapter 1 for how flood reports were processed, standardized and categorized in this analysis. 
Table 2: Summary of data used in analysis

\begin{tabular}{|c|c|c|}
\hline Variables & Description & Agency \\
\hline $\begin{array}{l}\text { Modified Topographic } \\
\text { Wetness Index (TWI) }\end{array}$ & $\begin{array}{l}\text { Estimates localized surface } \\
\text { accumulation based on } \\
\text { catchment area, runoff } \\
\text { coefficient, and } \\
\text { instantaneous slope. } \\
\text { Masked out TWI scores for } \\
\text { surface conveyance (i.e. } \\
\text { streams, ditches, curb, flow, } \\
\text { roof-tops, and wetlands). } \\
\text { Computed using } 2014 \\
\text { LiDAR at } 1 \mathrm{~m} \text { resolution }\end{array}$ & $\begin{array}{l}\text { City of Portland, Bureau of } \\
\text { Environmental Services, } 2018\end{array}$ \\
\hline $\begin{array}{l}\text { Citizen-observed } \\
\text { flood reports }(n=9804)\end{array}$ & $\begin{array}{l}\text { Flooding reports from six } \\
\text { different categories within } \\
\text { TrackIT database }\end{array}$ & $\begin{array}{l}\text { City of Portland, Bureau of } \\
\text { Transportation, TracklT } \\
\text { database, } 2010-2017\end{array}$ \\
\hline $\begin{array}{l}\text { Female headed } \\
\text { households }\end{array}$ & $\begin{array}{l}\text { Percent female-only } \\
\text { households per land area } \\
\text { of census tract }\end{array}$ & U.S. Census Bureau, 2010 \\
\hline Households age 65+ & $\begin{array}{l}\text { Percent households with } \\
\text { individuals age } 65+\text { per land } \\
\text { area } \\
\text { of census tract }\end{array}$ & U.S. Census Bureau, 2010 \\
\hline $\begin{array}{l}\text { Households with } \\
\text { children age } 18 \text { and } \\
\text { under }\end{array}$ & $\begin{array}{l}\text { Percent households with } \\
\text { individuals under } 18 \text { years } \\
\text { per land area of census tract }\end{array}$ & U.S. Census Bureau, 2010 \\
\hline $\begin{array}{l}\text { Multifamily (MFR) } \\
\text { housing inventory }\end{array}$ & $\begin{array}{l}\text { Percentage MFR taxlots per } \\
\text { land area of census tract, } \\
\text { and average age of MFR } \\
\text { taxlots per census tract }\end{array}$ & $\begin{array}{l}\text { Oregon Metro Regional Land } \\
\text { Information (RLIS), } 2016\end{array}$ \\
\hline Taxlots & $\begin{array}{l}\text { Percentage of single-family } \\
\text { residential (SFR), } \\
\text { commercial and industrial } \\
\text { taxlots per land area of } \\
\text { census tract, and average } \\
\text { age of all taxlots per census } \\
\text { tract }\end{array}$ & $\begin{array}{l}\text { Oregon Metro Regional Land } \\
\text { Information (RLIS), } 2018\end{array}$ \\
\hline $\begin{array}{l}\text { City vulnerability } \\
\text { analysis risk factors: } \\
\% \text { Renters, \% } \\
\text { Communities of Color } \\
\text { (CoC), \% Population } \\
\text { age } 25+\text { without a }\end{array}$ & $\begin{array}{l}\text { Four risk factors were } \\
\text { calculated as a percentage } \\
\text { per census tract. CoC refers } \\
\text { to all communities that are } \\
\text { not identified as "' non- } \\
\text { Hispanic whites" }\end{array}$ & $\begin{array}{l}\text { City of Portland, Bureau of } \\
\text { Planning and Sustainability: } \\
\text { 2012-2016 American Community } \\
\text { Survey (ACS) 5-Year Estimates } \\
\text { and 2010-2014 U.S. Department } \\
\text { of Housing and Urban }\end{array}$ \\
\hline
\end{tabular}


bachelor's degree, \%

Households with income

at or below $80 \% \mathrm{MFI}$
Development (HUD) and

Comprehensive Housing

Affordability Strategy (CHAS)

\subsubsection{Topographic Wetness Index (TWI)}

To compare citizen-observed flooding reports to a predictive static model of surface flow, this analysis used a topographic wetness index (TWI) created by BES to examine where localized surface flow accumulates based on topography. The use of a TWI is consistent with previous studies that have examined localized flood risk (Grab et al. 2009, Jalayer et al. 2014, Wu et al. 2016). TWI was originally created to predict regions vulnerable to overland flow from the saturation of land surfaces and stemmed from the TOPMODEL that modeled the dynamics of hydrologic fluxes of watersheds (Beven \& Kirkby 1979). A standard TWI is based on the following equation:

$T W I=\log (\alpha / \tan \beta)$, with $\alpha$ being the local upslope area per unit contour length and $\beta$ the local slope gradient.

While a standard TWI routes hydrologic flow between grid cells based primarily on slope in computer-simulated raster models in GIS, BES created a Modified TWI using Python scripting and GIS to calculate a runoff coefficient per cell based on slope, soil, vegetation, the stormwater collection system and impervious surface. This model routed flow accumulation based on a FD8 algorithm, which has proven to be successful in previous studies for routing upslope flow accumulation to all downhill neighboring cells in one of 8 directions 
(Seibert \& McGlynn 2007). To calculate the final modified TWI, BES used a 1meter resolution LiDAR digital elevation model (DEM) to determine instantaneous slope where each TWI was calculated. BES also masked out TWI scores in regions of expected surface conveyance, such as streams, ditches, curbs, wetlands, and rooftops since it is assumed that water will accumulate in these regions.

\subsubsection{Explanatory factors for social vulnerability to pluvial flood risk}

As previously stated, the main determinants of social vulnerability to urban flood risk are predominantly related to race and socio-economic status as discussed in previous literature (Elliot \& Pais 2006, Douglas et al. 2012, Rasch 2017, Romero-Lankao et al. 2014). Indicators for race and socio-economic status used in this analysis were based on the 2012 City of Portland Vulnerability Analysis that assessed the social vulnerability of different neighborhoods (Bates 2013). This analysis examined four risk factors: communities of color (i.e. all racial groups not identified as white non-Hispanic), renters, population age 25 plus without a bachelor's degree (BA), and those living at or below $80 \%$ of the median-family income (MFI) level (Bates 2013).

Additional socio-demographic variables, such as age and gender, were also used in this analysis based on a literature review of populations most vulnerable to urban flood risk and weather-related hazards (Denton 2002, Grineski et al. 2012, Romero-Lankao et al. 2014, Sansom et al. 2017). To 
understand the building characteristics associated with flood reports, this study chose to examine the percent of industrial, commercial and residential (i.e.

Single-family and Multi-family residential) land use categories and their average building age per census tract which is consistent with similar studies that have examined the built environment associated with urban flood risk (Jalayer et al. 2014, Jenkins et al. 2017, Koks et al. 2015, Krellenberg \& Welz 2017, Rothlisberger 2017).

3.2 Correlation-TWI and flood report density 
Figure 7 indicates the density of flood reports per census tract and the six major quadrants of Portland referenced in this study. Since reports were not evenly distributed across census tracts, this analysis chose to examine the mean density of citizen-observed flooding reports per census tract.

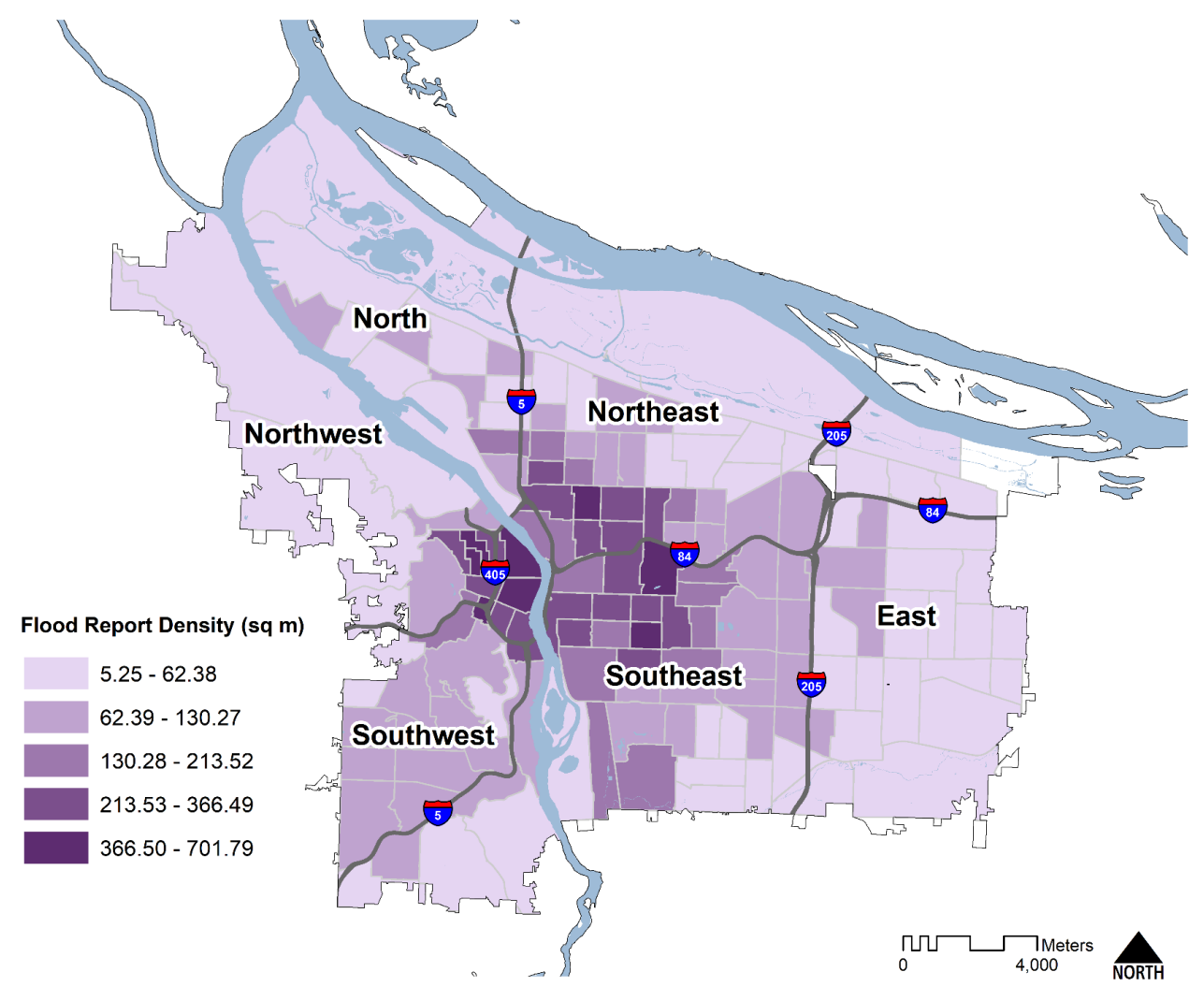

Figure 7: Density of flood reports per census tract (square meters) and the six major quadrants of Portland. 
A correlation between flood report density and the TWI was tested at two different scales: 5-acres (i.e. 12.6 square miles) and area of a census tract. A 5acre scale was used to be consistent with the collaborative effort of this study with BES as stormwater managers generated seven stormwater risk assessment maps that could be compared at a 5-acre hexagon scale (see example Figure 8). A Spearman Rank Correlation coefficient, which is a nonparametric measure of statistical dependence between two variables was used to account for the nonlinearity between flood reports and TWI estimates.

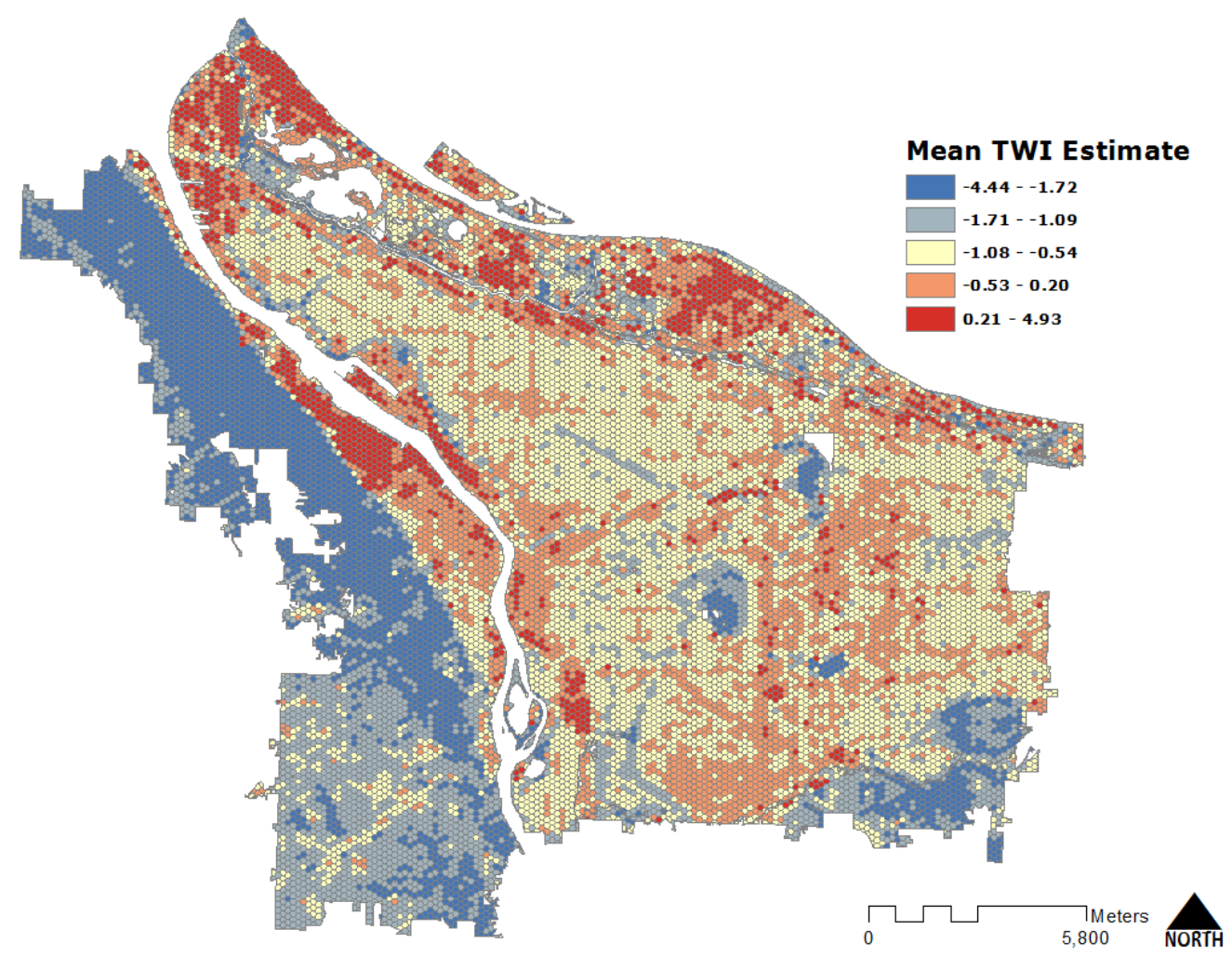

Figure 8: Mean Topographic Wetness Index (TWI) estimate at 5-acre hexagon scale 
A Local Bivariate Moran's I was used to test for spatial autocorrelation between the two variables, in which the null hypothesis for Moran's I assumes spatial randomness. Moran's I values range from -1 to +1 , and were tested for statistical significance (i.e. pseudo p-value) using 999 permutations, which calculates the random distribution of observed values over the locations (Wang et al. 2017). Therefore, values close to -1 indicate negative spatial autocorrelation, while values close to +1 indicate positive spatial autocorrelation, and results from the permutation test indicate the significance of the Moran's I value. Moran's I values for each set of variables were mapped using Local Indicators of Spatial Association (LISA) cluster maps.

At the 5-acre hexagon scale, the relationship between the density of reports and the mean and max TWI estimate per hexagon was tested. At the census tract scale, the mean and max TWI estimate was also tested, as well as a percentage of each census tract that had TWI values within $5 \%$ (i.e. $95 \%$ confidence interval) and $10 \%$ from the mean.

\subsection{Regression Analysis_Flood reports and socio-demographic and building characteristics}

The regression analysis of identifying socio-demographic and building characteristic factors affecting flood report density consists of three major parts: selection of 17 explanatory variables using an OLS model, a limited model to test for spatial autocorrelation using a Spatial Lag Regression, and a Geographically 
Weighted Regression (GWR) of the final model to test for local variations amongst variables in space (see Table 3).

Table 3: List of 17 explanatory variables used in analysis. Indicating the Spearman Rank Correlation Coefficient, significance value (Sig.), Variance Inflation Factor (VIF) and number of observations $(\mathrm{N})$

\begin{tabular}{|c|c|c|c|c|}
\hline No. & Variable & $\begin{array}{l}\text { Spearman } \\
\text { Correlation }\end{array}$ & VIF & $\mathbf{N}$ \\
\hline 1 & $\%$ Renters & $0.336^{* * *}$ & 2.26 & 143 \\
\hline 2 & $\% \mathrm{CoC}$ & $-0.424^{* * *}$ & & \\
\hline 3 & $\%$ Households $\leq 80 \% \mathrm{MFI}$ & -0.15 & & \\
\hline 4 & $\%$ Age $25+$ without $B A$ & $-0.5784^{* * *}$ & 2.47 & 143 \\
\hline 5 & $\%$ TWI estimate within $10 \% \mathrm{Cl}$ & -0.03 & & \\
\hline 6 & $\%$ Households Age 65+ & $-0.378^{* * *}$ & & \\
\hline 7 & \% Female Headed Households & $-0.523^{* * *}$ & & \\
\hline 8 & $\begin{array}{l}\% \text { Households with children age } 18 \\
\text { and under }\end{array}$ & $-0.509^{* * *}$ & 2.55 & 143 \\
\hline 9 & \% Commercial buildings & $0.349^{* * *}$ & & \\
\hline 10 & $\%$ Industrial buildings & -0.12 & & \\
\hline 11 & $\%$ SFR buildings & $-0.184^{*}$ & & \\
\hline 12 & $\%$ MFR buildings & $0.239^{* *}$ & & \\
\hline 13 & Avg. Age of Commercial buildings & $0.538^{* * *}$ & 1.50 & 143 \\
\hline 14 & Avg. Age of Industrial buildings & 0.02 & & \\
\hline 15 & Avg. Age of SFR buildings & $0.706^{* * *}$ & 1.70 & 143 \\
\hline 16 & Avg. Age pf MFR buildings & $0.531^{* * *}$ & & \\
\hline 17 & Avg. Age of all buildings & $0.721^{* * *}$ & & \\
\hline
\end{tabular}

\subsubsection{OLS and Variable Selection}

As previously stated, the distribution of flooding reports was not normally distributed across space. To meet the assumptions of independence, normality, and equal variance of the response variable to run an initial OLS model, this study used a natural log transformation of flood report density. 
To reduce the number of predictors for completing an initial OLS model, a Spearman Rank correlation coefficient and test for multicollinearity were employed on all 17 explanatory variables using the statistical program $R(R$ Studio 2016) (see Table 3). This process limited predictors that did not have a correlation coefficient with the response variable above 0.50 and with $95 \%$ confidence (i.e. p < 0.05). This study also removed variables that showed signs of multicollinearity with other predictor variables.

Multicollinearity refers to correlations among the predictor variables which make it difficult to accurately estimate regression parameters and tease apart the unique contributions of each of the predictor variables to variation in the response variable. A variance inflation factor (VIF) was used to test for multicollinearity between variables which measures how much variances of the regression coefficients are inflated compared to when the variables are not linearly correlated. This analysis followed suit with previous studies that a VIF value greater than 5 suggests possible multicollinearity, while a VIF greater than 10 is strong evidence that multicollinearity exists and is influential within the model (Forgey 1994). This analysis also kept predictors whose coefficients did not change sign (i.e. negative to positive) when running the OLS model to not misspecify the model.

In looking at the results of all 17 explanatory variables in Table 3 , seven variables had a significant correlation with flood report density at the predetermined significance level. Before running a full OLS model with seven 
predictors, this analysis assessed the VIF between variables, finding that the average age of all buildings showed signs of high multicollinearity with the other four predictors of building age, thus this variable was removed from the full model. Additionally, percent of renters maintained a positive correlation with flood report density, and since this analysis assumed this would be a significant indicator of flood reports within central regions of the city, the variable was maintained to run the full OLS model. After running a full OLS with seven significant predictors, five variables were significant at the pre-determined significance level: percentage of renters, percentage age $25+$ without a bachelor's degree (BA), percentage of households with children age 18 and under, average age of commercial buildings and average age of single-family residential (SFR) buildings (see Figure 9). 

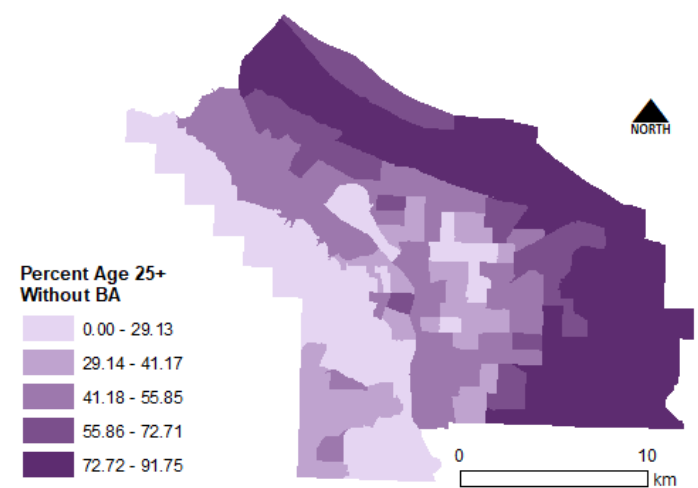

(a)

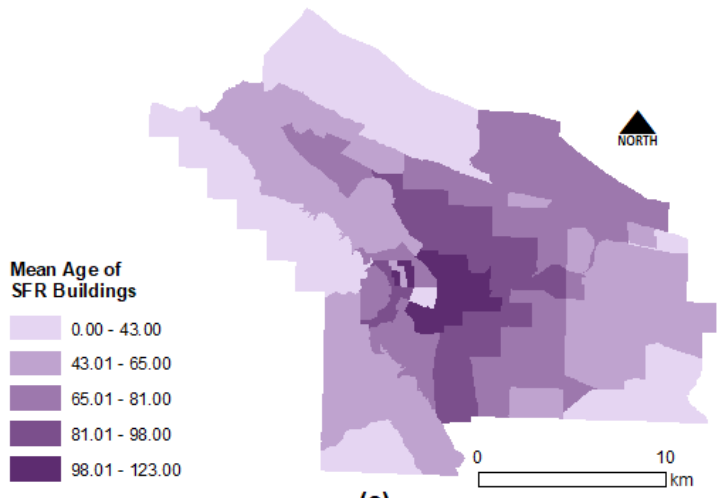

(c)

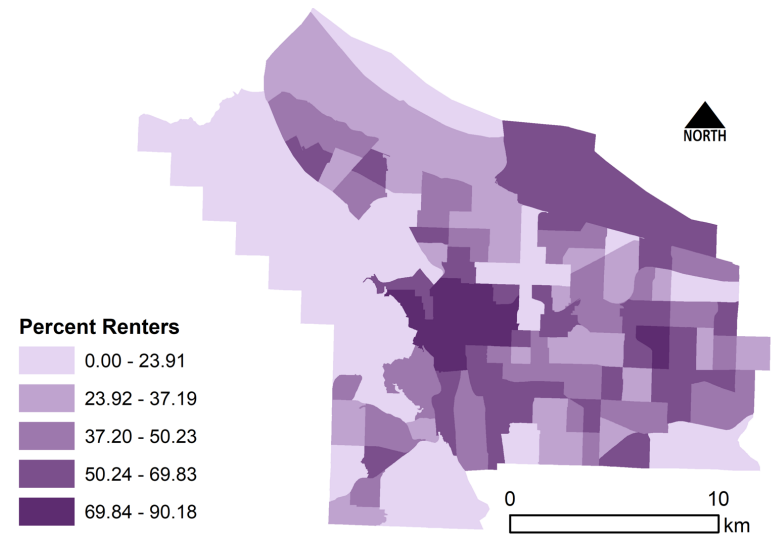

(e)

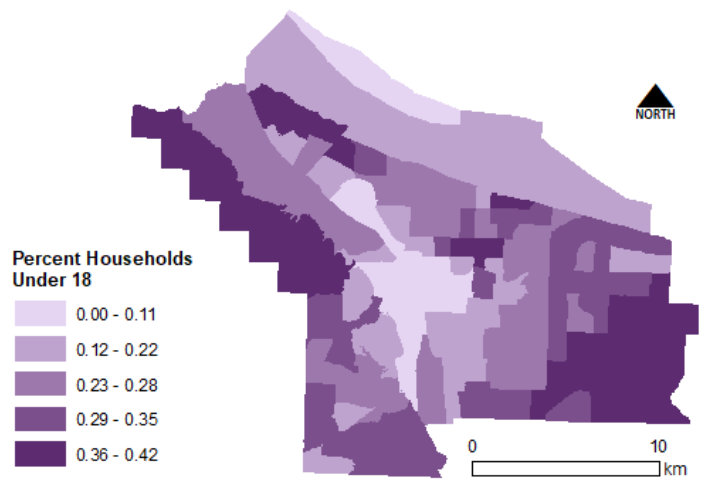

(b)

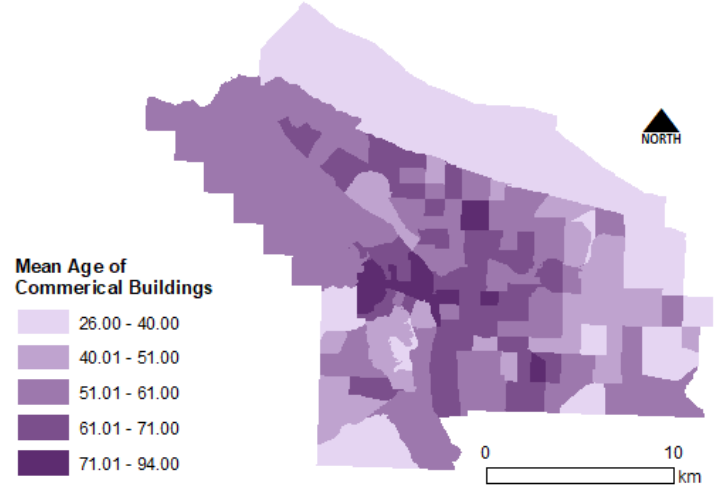

(d)

Figure 9: Spatial patterns of five predicator variables used in final model. a) Percentage 25+ without a bachelor's degree b) Percent households with children under $18 \mathrm{c}$ ) Mean Age of SingleFamily Residential buildings d) Mean age of commercial buildings e) Percent renters 


\subsubsection{Spatial Lag Regression}

A Spatial Lag Regression was run for the final five predictors to test for spatial autocorrelation in the residuals using the statistical program GeoDa (Anselin et al. 2006). This test relied on a hexagon spatial weights matrix which defines neighbors by the presence of a common edge between polygons (Anselin et al. 2006). A spatial lag was chosen over a spatial error regression based on the significance of the Lagrange Multiplier (lag) and its Robust LM (lag) in the diagnostics for spatial dependence, which indicated that a Spatial Lag model was a good alternative to an OLS. A Bivariate Moran's I was then computed on the residuals and the lag of the residuals of the Spatial Lag model, in which significance of the Moran's I was determined based on 999 permutations. For this model to not exhibit spatial autocorrelation and instead exude spatial randomness amongst variables, the $p$-value should not be significant at the $95 \%$ confidence level (i.e. p-value < 0.05 ).

\subsubsection{Geographically Weighted Regression}

A geographically weighted regression (GWR), a local linear regression, was used to model the relationship between the density of flood reports and socio-demographic and building characteristics using $\mathrm{R}$. While a traditional linear regression model, OLS, quantifies the relationship between dependent and possible explanatory variables, it is not well-suited for modeling spatial 
heterogeneity and non-stationarity of geographical data. A GWR is known to capture the variation of spatial relationships across space by analyzing the spatial dependency of each variable using either a fixed or adaptive spatial weight between each set of parameters (Chun et al. 2017). Additionally, a GWR has been successful in previous studies for modeling spatially explicit relationships between natural disasters and explanatory factors (Chun et al. 2017, Wang et al. 2016).

The formula for a GWR is as follows:

$$
\begin{aligned}
& y_{i}=\beta_{0}(i)+\beta_{1}(i) X_{1 i}+\beta_{2}(i) X_{2 i}+\ldots . \beta_{n}(i) X_{n i}+£_{1} \\
& \beta(i)=\left(X^{\top} W(i) X\right)^{-1} X^{\top} W(i) Y
\end{aligned}
$$

where (i) is the coordinates of the points in space, and $\mathrm{W}(\mathrm{i})$ is a matrix of weights specific to each location (i), allowing for a greater weight to be given to observations nearer to (i). $\beta$ represents each predictor variable tested, $y$ is the number of observations of the dependent variable, and $\mathrm{X}$ is a matrix of independent variables (Chun et al. 2017). To be consistent with similar studies that have used a GWR to model the spatial relationship of urban flooding with explanatory variables, this study used an adaptive bi-square kernel method for geographical weighting to estimate local coefficients and bandwidth size since the points of observation (i.e. census tracts) were of irregular distances (Chun et al. 2017). 


\section{Results}

\subsection{TWI and Flood Report Correlation}

Table 4 shows the correlation and spatial autocorrelation of mean flood report density and TWI estimates at the 5-acre hexagon and census tract scale. Overall, there was not a high degree of correlation between the mean density of flood reports and TWI at both scales. At the 5-acre hexagon scale, both the mean and max TWI estimates were positively correlated with mean flood report density, but Mean TWI showed a statistically significant correlation with mean flood report density at a $5 \%$ significance level. At the census tract scale, only the max TWI showed a statistically significant negative correlation with mean flood report density at a $5 \%$ significance level. There were three statistically significant spatial autocorrelations found as shown by Moran's I values. At the 5-acre hexagon scale, the mean TWI showed statistically significant spatial autocorrelation with flood reports at a $5 \%$ significance level. At the census tract scale, the max TWI and percent of census tracts with TWI values within two standard deviations also exhibited statistically significant spatial autocorrelation at a $5 \%$ significance level. 
Table 4: Correlation of mean flood report density and topographic wetness index (TWI) estimate at 5-acre hexagon and census tract scale. Table indicates the Spearman Rank Correlation Coefficient and Moran's I, and the significance of these two values.

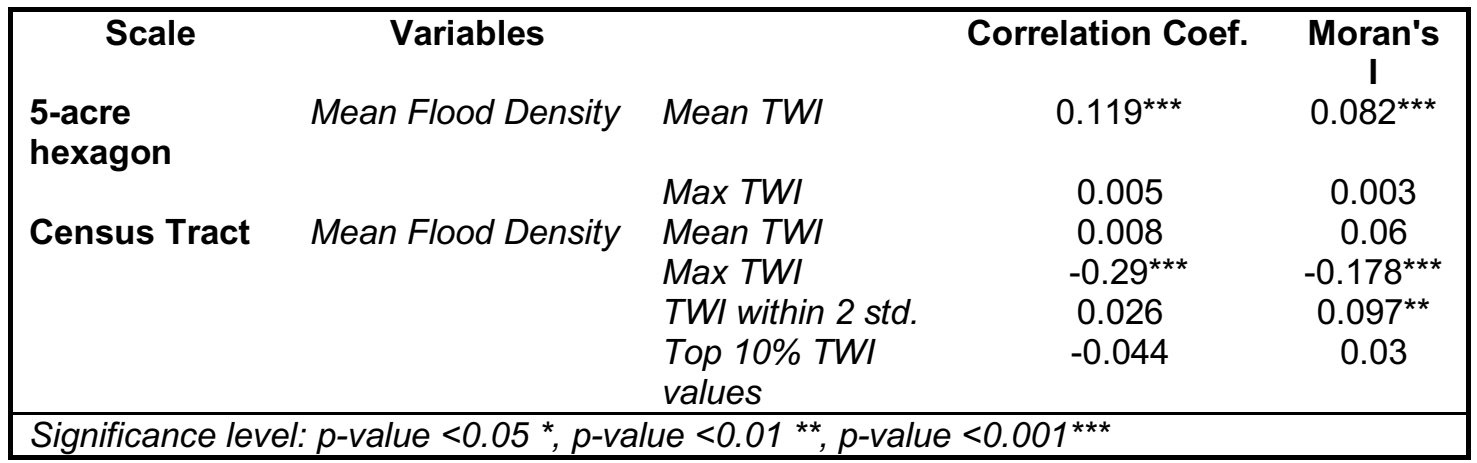

To validate the spatial patterns of significant results shown in Table 4, Figure 10a shows significant positive spatial clustering of mean TWI and flood reports at the 5-acre hexagon scale in the central regions of the city, with low negative spatial clustering in the NW, SW and outer east regions of the city.

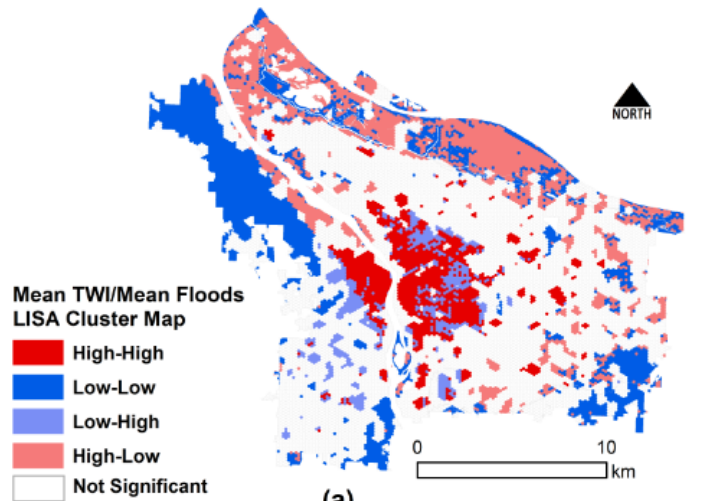

(a)

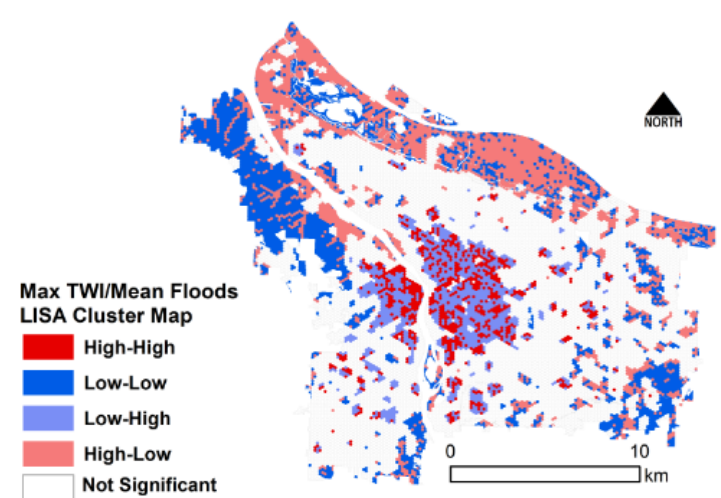

(b)

Figure 10: LISA cluster maps of flood report density and TWI at 5-acre hexagon scale. Red indicates positive spatial autocorrelation and blue indicates negative spatial autocorrelation, while light blue and light pink indicate spatial outliers. a) Mean TWI and mean flood report density. b) Max TWI and mean flood report density 
At the census tract scale, max TWI and flood reports are significantly positively spatially clustered in the central downtown and eastside regions of the city with significant negative spatial clustering further east of the central city (Figure 11b).

Figure 11c, the percent of TWI estimates within two standard deviations, shows a similar spatial pattern to the max TWI, but indicates a mostly positive significant spatial clustering in central regions of the city and includes fewer spatial outliers.
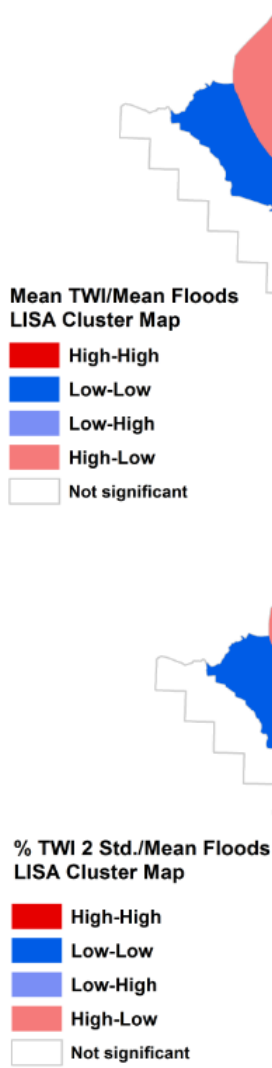

(a)

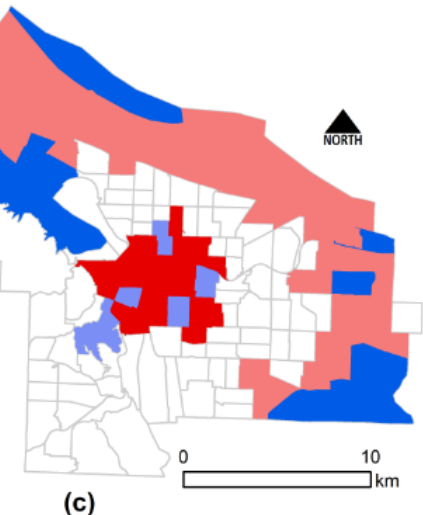

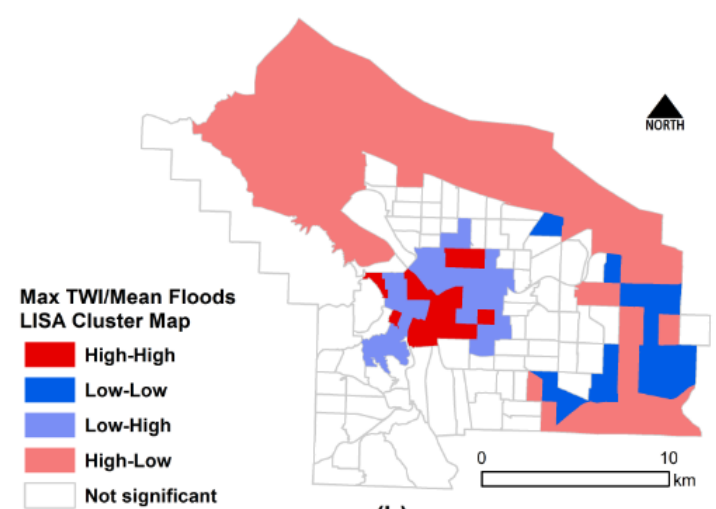

(b)

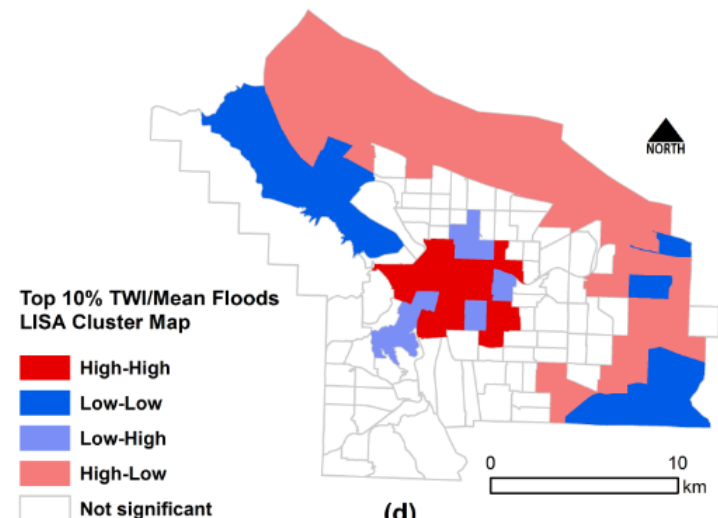

(d)

Figure 11: LISA cluster maps of flood report density and TWI at census tract scale. Red indicates positive spatial autocorrelation and blue indicates negative spatial autocorrelation, while light blue and light pink indicate spatial outliers. a) Mean TWI and mean flood report density. b) Max TWI and mean flood report density. c) \% TWI estimates within two standard deviations and mean flood report density. d) Top 10\% of TWI estimates and mean flood report density 


\subsection{Flood Reports and Socio-demographic and Building Characteristics}

\subsubsection{OLS and Spatial Lag model comparison}

Table 5 indicates the results from the minimal OLS and Spatial lag models with five predictor variables to run the GWR model. Results from the GWR are not shown as the coefficient values did not change from the OLS model, and a GWR does not typically rely on the use of significance levels for coefficients (i.e. p-value). In comparing results from the OLS and Spatial Lag models, we found model coefficient values changed slightly but signs of the coefficients did not change. Furthermore, only one of the variables (i.e. Average Age of Commercial buildings) dropped one level of significance from the OLS to Spatial Lag model.

Table 5: Statistical comparison between OLS and Spatial Lag Regression models:

\begin{tabular}{|lcc|}
\hline & OLS & Spatial Lag \\
\hline Variable & Coefficient & Coefficient \\
$\%$ Renters & $0.0101^{* * *}$ & $0.006^{\star * *}$ \\
$\%$ Age 25+ without BA & $-0.0103^{* * *}$ & $-0.005^{* * *}$ \\
$\%$ Households with children age 18 and & $0.8421^{* *}$ & $0.724^{* *}$ \\
under & $0.0056^{* *}$ & $0.003^{*}$ \\
Avg. Age of Commercial buildings & $0.006^{* * *}$ & $0.003^{* * *}$ \\
Avg. Age of SFR buildings & 29.85 & -5.69 \\
\hline AIC & 0.62 & 0.74 \\
Adjusted R & \\
\hline Significance level: $p$-value $<0.05^{*}, p$-value $<0.01^{* *}, p$-value $<0.001^{* * *}$ \\
\hline
\end{tabular}

\subsubsection{Variable Coefficients of GWR model}


Figure 12a-d indicates the significant coefficients from the GWR model. Significance level was determined based on a $95 \%$ confidence of the t-value associated with each coefficient, in which $\mathrm{t}$-values of $+/-1.96$ were used as the critical region to assess significance of coefficients, which is consistent with previous GWR analyses (Matthews \& Yang 2012). Census tracts that appear white showed no significance according to the t-value. Additionally, red census tracts indicate significant positive model coefficients while blue census tracts indicate significant negative model coefficients.
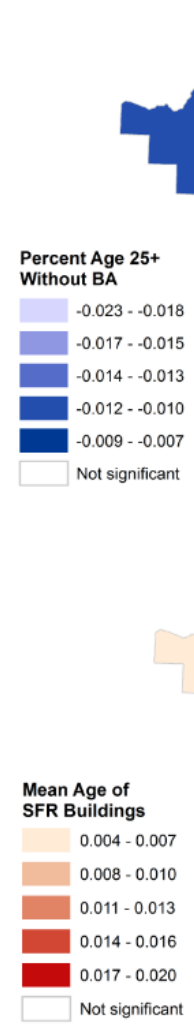

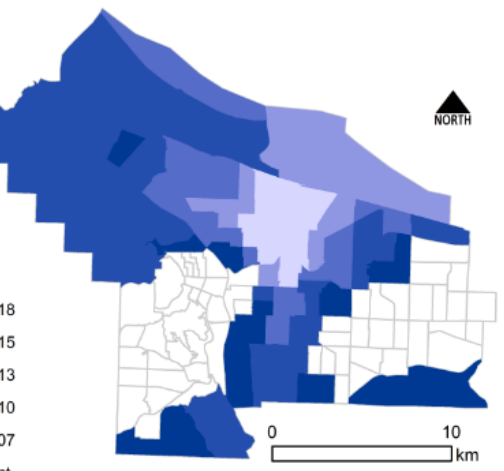

(a)

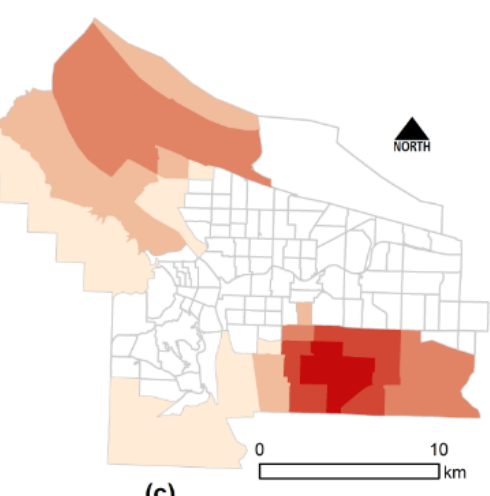

(c)

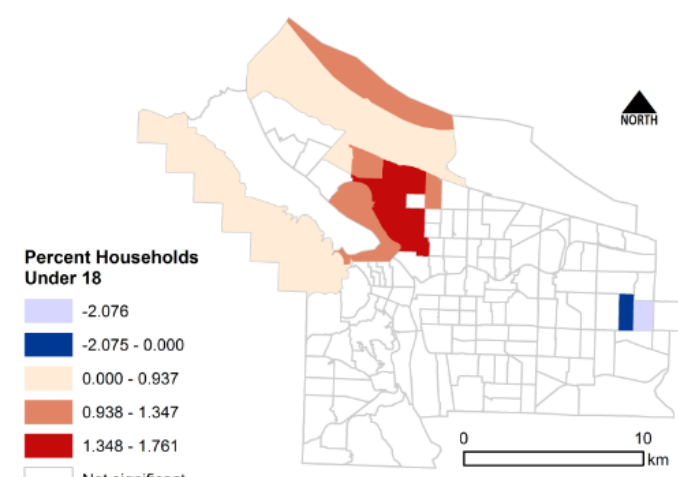

(b)

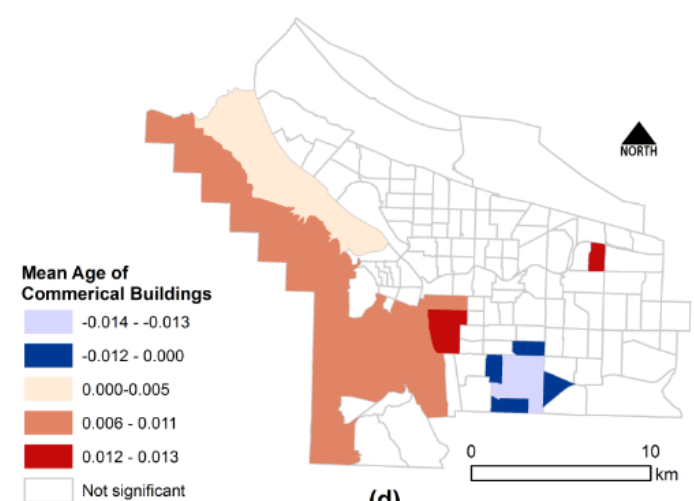

(d)

Figure 12: Significant coefficients from the GWR model. a) Percent of population age 25+ without a BA. b) Percent of households with children under 18 years of age. c) Mean age of single-family residential (SFR) buildings. d) Mean age of commercial buildings. 
In examining the results of the percent of population age $25+$ without a BA in Figure 12a, which is the only variable with an entirely negative relationship with flood density (i.e. $\beta=-.01$ ), significant negative coefficients decreased (i.e. 0.023- -0.007$)$ in central regions of the city that had the most flood reports. This finding could mean that young adults without a college education are less likely to report flooding as the density of reports are clustered within central regions of the city, and the majority of young adults without a BA live east of the city (see Figure 9a). This could be indicative of those with less education living in regions with more affordable housing since central regions of the city are more desirable, thus more expensive.

Looking at the percent of households with children under 18 in Figure 12b, a strong positive correlation with flood report density was found in the far NE region of the city as significant positive coefficients ranged from $0.000-1.761$, and a strong negative correlation with flood report density $(0.000--2.076)$ in the outer eastern regions of the city. These findings are comparable to the density of families with children clustered within upper NW, NE and far eastern regions of the city (see Figure 9b). While these specific regions do not see a high density of flood reports, they are still indicative of the social vulnerability of families who report flooding, as families further east may not have the same response rate to report flooding as families in the upper NE region of the city based on eastern regions having a lower socio-economic status than NE regions. 
Figure 12c represents the mean age of single-family residential (i.e. SFR) buildings, in which significant positive coefficients ranged from 0.004-.020, indicating that an increase in the mean age of SFR buildings increased flood report calls in the SE regions of the city. This finding is highly related with older infrastructure in central regions of the city, leading this study to believe that flooding is predominantly occurring or within close proximity to older single-family residential homes (see Figure 9c). This finding could also be indicative of the older pipe networks surrounding these older homes, which are almost entirely within the combined sewer system.

Figure 12d indicates the mean age of commercial buildings, which had significant positive coefficients ranging from $0.000-.013$, and significant negative coefficients ranging from $-0.014-0.000$. The map shows a positive correlation with flood reports in the downtown and SW regions of the city, and a negative correlation with flood reports in the SE regions of the city. This finding is also indicative of older infrastructure and the density of commercial buildings within downtown and central regions of the city, as outer SE regions do not have a high density of commercial buildings, and if there are commercial buildings present, they were most likely developed after commercial building in central regions. This study chose not to interpret the significant coefficients from the percent of renters as the spatial distribution of coefficients exhibit potential misspecification of the model, which could be due to the initial degree of correlation between percent of renters and flood report density below $50 \%$. 
In interpreting the coefficients in relation to the natural log transformation of flood report density, the following formula $\left(e^{\beta}-1\right) * 100$ was used to understand the percent change between flood report density and predictor variables. $\beta$ used in this formula is the coefficient value for each predictor variable from the OLS model output, which is the same as the global coefficient in the GWR model (see Table 5). Therefore, for every percent increase in population age $25+$ without a $\mathrm{BA}$, flood report density decreases by $1 \%$. For every percent increase in households with children under 18 years of age, flood report density increases by $132 \%$. For every percent increase in average single-family residential building age, flood report density increases by $.06 \%$. For every percent increase in average commercial building age, flood report density increases by $.05 \%$.

\subsubsection{Comparison of OLS, Spatial Lag and GWR models}

Table 6 compares diagnostics from the OLS, Spatial Lag and GWR models using an Adjusted $\mathrm{R}^{2}$, Akaike Information Criterion (AIC) and Moran's I. The adjusted $R^{2}$ is highest for the GWR model $(0.83)$, followed by the Spatial Lag (0.74) and OLS (0.62) models, respectively. The AIC, which estimates the quality of the model, had the lowest value for the GWR model (i.e. -61.07) and the highest value for the OLS model (i.e. 29.85), meaning the GWR model performed best since a lower AIC indicates a better model fit. In examining the Moran's I of 
the residuals, the OLS and GWR models detected spatial autocorrelation in the residuals since both Moran's I values were significant at a 95\% confidence level (i.e. $p$-value $<0.05$ ). On the other hand, the Spatial Lag model did not detect spatial autocorrelation as the Moran's I value was not significant with $95 \%$ confidence.

Table 6: Statistical comparison between OLS, Spatial Lag and GWR models

\begin{tabular}{|lccc|}
\hline \multicolumn{1}{|c}{ Statistics } & OLS & Spatial Lag & GWR \\
\hline Number of Observations & 143 & 143 & 143 \\
Adjusted $R^{2}$ & 0.62 & 0.74 & 0.83 \\
AIC & 29.85 & -5.69 & -61.07 \\
Moran's I (residuals) & $.219^{* * *}$ & -0.02 & $.739^{* * *}$ \\
\hline Significance level: $p$-value $<0.05^{*}, p$-value $<0.01^{* *}, p$-value $<0.001^{* * *}$ \\
\hline
\end{tabular}

\subsubsection{GWR Model Validation}

Evaluating the performance of the GWR model relies on the estimated local $R^{2}$ values and standardized residuals. The local $R^{2}$ indicates how well the GWR model fits the observed y values, and values range between $0-1$. The standardized residuals indicate over and under predictions of the regression model, as clustering of over or under predictions is evidence for potentially missing a key explanatory variable. Values under -2.5 standard deviations and above 2.5 standard deviations represent statistically significant residuals (i.e. $95 \%$ confidence level), and are indicative of a misspecified GWR model. 
Figure 13a shows the local $R^{2}$ values, in which no values were below 0.51 , meaning the model performed fairly well. The highest performance (i.e. darkest red) is clustered in the SE, NE, and SW regions of the city, and the lower clustering (i.e. beige) is shown in the central downtown, NE and SW regions of the city. Figure 13b indicates the standardized residuals, in which only one census tract in the far NE corner of Portland near the Columbia River was under -2.5 standard deviations, which indicates the model did not under represent the relationship between flood density and predictor variables. Additionally, the model did not exhibit residuals above 2.5 standard deviations, indicating the model did not over represent the relationship between variables, and is not misspecified by missing a key explanatory variable.

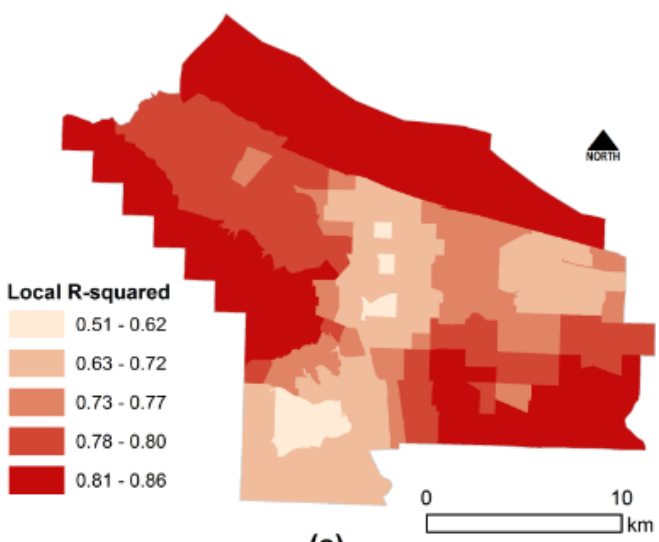

(a)

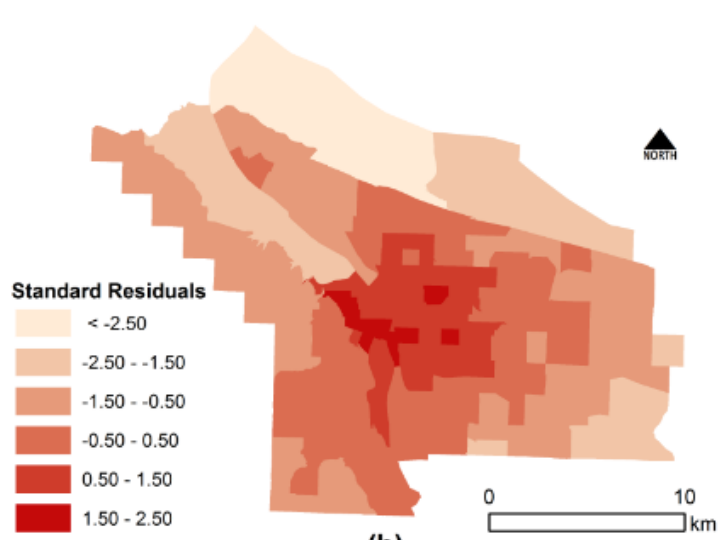

(b)

Figure 13: GWR model outputs. a) Local R-squared b) Standardized residuals 


\section{Discussion}

\subsection{TWI and flood report correlation}

Results from testing the correlation between flood report density and TWI estimates indicated there was a correlation between the two variables, but not a strong correlation. This could be due to the fact that flood reports were not evenly spread across the city and instead were clustered in specific regions of the city (i.e. central downtown and eastside), while the TWI is a continuous estimate across the surface. Additionally, correlations at the 5-acre hexagon scale were all positive, while correlations at the census tract scale were positive and negative. This could be because testing the correlation at a smaller scale maintains the integrity of the TWI estimate since it was originally calculated at a 1-meter resolution and attributing that value to the size of a census tract could obscure the detail of the TWI data.

Understanding the results at the 5-acre hexagon scale can be an issue of data aggregation as the max TWI and mean flood report density values are different estimates, thus comparing a mean TWI value against a mean flood report density value is more logical. In interpreting the results at the census tract scale, a negative spatial association with max TWI is presumed since associating a max TWI value across an entire census tract in relation to the density of flood reports is an issue of scale. Associating a percentage of census tracts with TWI estimates within two standard deviations is presumed to be more spatially 
correlated with flood report density since this is a much finer estimate of TWI that only considers the most statistically significant (i.e. 95\% confidence level) TWI estimates.

\subsection{Socio-demographic and building characteristics of flood reports}

Results from performing a GWR to model the relationship between flood report density and socio-demographic and building characteristics proved to be more successful than a standard OLS or Spatial Lag Regression models. Since OLS and spatial regression are both global models, they assume stationary spatial process, which we know the density of flood reports and explanatory variables are not stationary across space. While global regression models are aspatial and location independent, a GWR is a spatial and location dependent model, which allows us to examine how spatial relationships vary across space. 
In interpreting the spatial patterns of GWR coefficients in relation to sociodemographic characteristics, it is important to acknowledge the similarity of these results to the most recent economic vulnerability assessment study from the City of Portland, Bureau of Planning and Sustainability (BPS) that indicates the most vulnerable regions of the city based on four risk factors related to race and socioeconomic status used in this analysis (Bates 2013, see Figure 14).

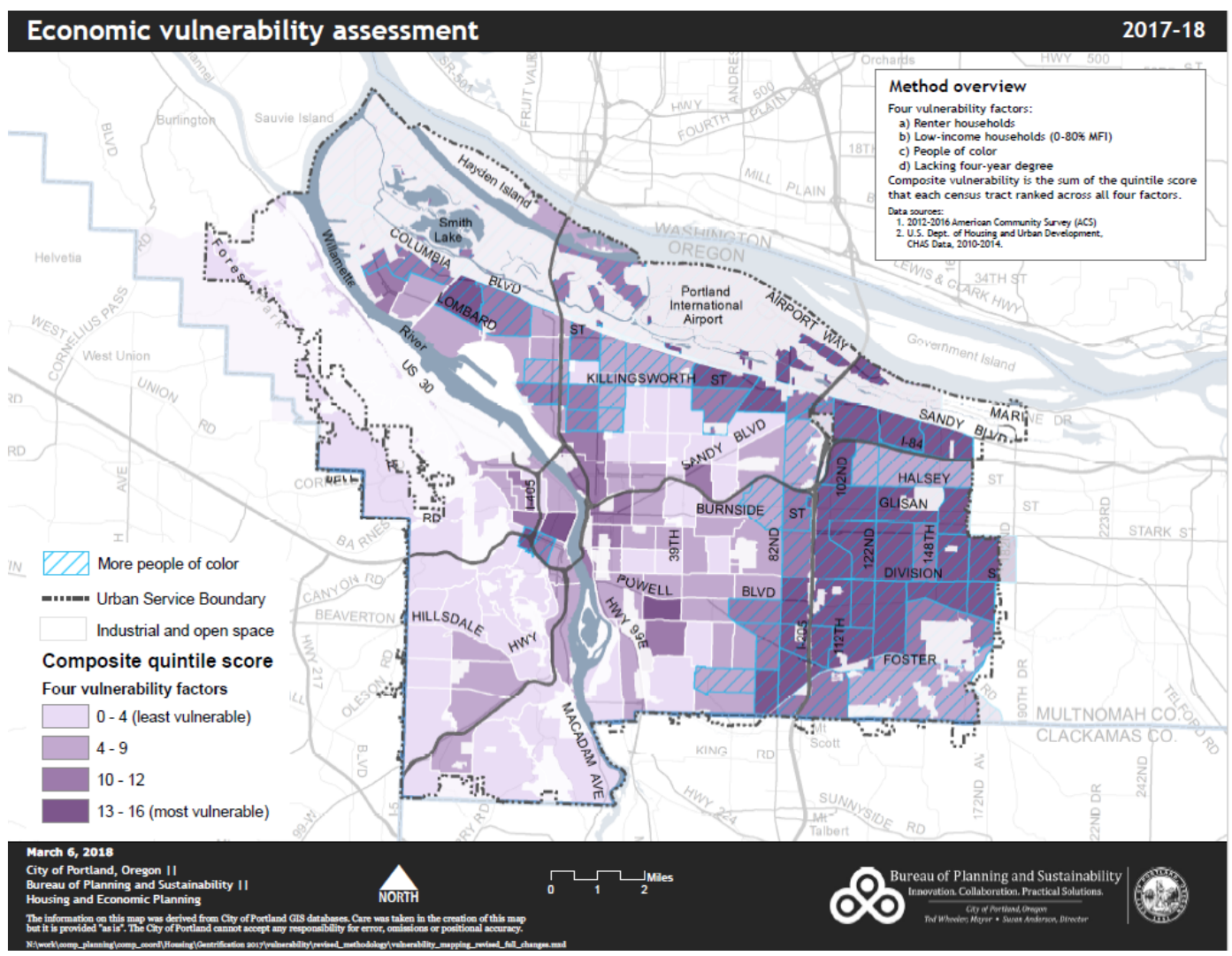

Figure 14: City of Portland, Bureau of Planning and Sustainability (BPS) Economic Vulnerability Assessment Map. Four risk factors are scaled from 0-16, with 0 being the lowest vulnerability and 16 the highest vulnerability (Bates 2013).

The only coefficient that had an entirely negative correlation with flood reports was the percentage of the population age $25+$ without a BA. This is not 
surprising in comparison to previous studies that have concluded that lower education levels contribute to a lower socio-economic status, thus higher social vulnerability when a natural hazard occurs due to a lack of knowledge, preparedness and support before and after a natural hazard occurs (Grineski et al. 2012, Rasch 2017, Romero-Lankao et al. 2014). Results from percent of households with children age 18 and under indicate that households in the NE quadrant of the city report flooding more often, while households further east do not report flooding as often. This could be indicative of high vulnerability of households further east since age (i.e. youth and elderly) has shown to elicit a lower response rate when a natural hazard occurs (Grineski et al. 2012, Rasch 2017, Romero-Lankao et al. 2014).

In interpreting the spatial patterns of GWR coefficients in terms of building characteristics, the age of infrastructure and density of buildings showed the most relationship with flood report density. The strongest relationship between the mean age of commercial buildings and flood report density was found within the CSS region, which is made up of older buildings, and where the highest concentration of commercial business resides in the city. Results from the mean age of SFR buildings were also not surprising since the clustering of positive coefficients were within SE regions of the city that do not have as high of a density of new MFR buildings as central regions of the city that are being developed more rapidly. 
It should be acknowledged that predictor variables were chosen based on a $5 \%$ significance level, which could create for potential variables being left out of the model. For instance, had a 10\% significance level been used, this could account for additional relationships with flood report density that are more indicative of a practical significance, instead of a statistical significance. For example, this study expected communities of color to be negatively correlated with flood report density since most communities of color live east of the central city, and most flood reports were generated in the central city. Had this study increased the significance level (i.e. $90 \%$ confidence level) when initially running the OLS model, this variable could have been represented in relation to flood report density.

\section{Conclusions}

This portion of the study aimed to address if citizen-observed flooding reports are correlated with known topographic characteristics (i.e. TWI) that contribute to surface flooding over space, and furthermore, what are the sociodemographic and building characteristics associated with flooding reports.

While this research found significant correlations between flood reports and a TWI at both the 5-acre and census tract scale, the correlation at a 5-acre hexagon scale showed only positive correlations, while the census tract scale had both positive and negative correlations. Flood reports and TWI were 
positively correlated within central regions of the city, and negatively correlated within SW, upper NE and far eastern regions of the city.

This research found a GWR to model the relationship between flood report density and socio-demographic and building characteristics more adequately than an OLS or Spatial Regression model. Results indicated the percentage of the population age $25+$ without a BA had a significantly negative correlation with flood reports across space, while mean age of SFR buildings had a significantly positive relationship in places with flood reports across space. Percent of households with population age 18 and under, and mean age of commercial buildings both had significantly negative and positive relationships with flood reports over space.

While results from the GWR model are helpful for understanding the relation between flood reports and socio-demographic and building characteristics, it is important to acknowledge the limitations of using participatory spatial data for flood risk analyses. As previously mentioned, participatory spatial data is completely reliant on how well the data was collected and processed, but more importantly, it is completely reliant on citizens who wish to participate or have the resources and knowledge to participate. Therefore, there could be potential barriers for certain communities to make a flooding complaint to the city.

As previously mentioned, studies have alluded to the fact that low-income and minority communities do not have the proper knowledge and support to 
assess a flooding event before and after it occurs (Douglas et al. 2012, Elliot \& Pais 2006, Romero-Lankao et al. 2014). While results from this analysis are not entirely in line with these conclusions, it is still important to recognize the differences in socio-economic status amongst communities in Portland that could have contributed to more affluent communities reporting flooding more often. While flood reports are not necessarily spatially comprehensive, the highest density of reports were generated in central regions of the city where those of a lower social vulnerability reside (see Figures 7 and 14).

In relating these findings to core environmental justice (EJ) theories, it is important to acknowledge that participation in an individual's own justice is a part of the process that creates EJ justices or injustices (Schlosberg 2004). Schlosberg (2004) examined the importance of focusing on the processes that create unequal distribution of injustices through an individual's own participation and social recognition within society. If low-income and minority communities are not encouraged to directly participate in their own justice, they will not feel empowered to do so, which leads to a lack of motivation and resilience of these communities over time. Furthermore, previous research has shown that incorporating the opinion of marginalized communities directly into an analysis creates for more realistic equitable decisions (Chakraborty et al. 2016).

There are clearly inherent biases embedded within this dataset that are problematic for city flood risk management and planning. While the city does not rely solely on citizen-inputted data for flood risk assessment, citizen-inputted data 
is still the only ground-truth perspective of where localized pluvial flooding occurs, thus it will continue to be incorporated in flood risk analyses along with predictive modeling. This creates a repetitive cycle of flood risk being analyzed through data that might not be representative of all communities affected by flooding.

Additionally, the city relies on flood risk maps to determine areas of prioritization for upgrading stormwater systems and stormwater green infrastructure (SGI). While most flooding does occur in the downtown and central regions of the city, there is still substantial flooding that occurs within the outer eastern regions of the city due to flatter topography and older sewer systems in place. Since these regions are not within the most densely populated and hightraffic areas of the city, they do not receive the same level of attention. This can create spatial injustices of SGI and overall, access to greenspace in the city over time, as previous studies which examined the inequalities associated with green space in urban environments have shown (Agyeman et al. 2002, Heynen et al. 2006). Therefore, it is important for the city to recognize the spatial patterns between vulnerability and future stormwater system planning. 


\section{Overall Concluding Thoughts}

The objective of this research was to examine the spatial characteristics of pluvial flooding, and the validity of using participatory spatial data to evaluate urban flood risk in Portland, OR from 2010-2017. This research aimed to explore how future stormwater management and flood risk planning can better address the physical and social dimensions of flood vulnerability through the biophysical processes and socioeconomic characteristics that exist amongst communities in Portland.

Both chapters addressed the caveats of using participatory spatial data within flood risk analyses, as issues of reliability and credibility need to be considered when drawing conclusions from participatory data. In terms of data collection and processing, it is important to acknowledge the inherent problems and biases this process introduces, thus data processing should attempt to minimize human error as much as possible by further standardizing how the data gets inputted and translated. This study encourages the city to improve their web application for reporting flooding, as users would be able to directly place a point of flooding on a map, and answer a series of questions that allow only certain options as a response. This would alleviate a lot of translation issues and potential language barriers between city practitioners and citizens reporting flooding.

While findings from this analysis help to understand the correlation between citizen-observed flooding reports with predictive modeling and socio- 
demographic and building characteristics, it is important to not draw absolute conclusions from participatory spatial data since the data is reliant on who can participate. Therefore, it is important for city governments to establish trust and a common language with residents of all communities and encourage participation in city planning by offering classes and resources to share information about local efforts. If city practitioners cannot directly communicate or find barriers to communicate with marginalized communities, they should partner with local social justice organizations to find a common language that can be understood by both parties. This could be done through survey methods or focus groups to understand the potential barriers and discomforts marginalized communities might face in participating in citywide flood reporting. Additionally, city practitioners should be encouraged to include the perspective of marginalized communities directly into their risk analysis from the very beginning, which will alleviate issues of equity coming into question after an analysis has already been completed. 


\section{References}

Agyeman, J., Bullard, R., \& Evans, B. 2002. Exploring the Nexus: Bringing Together Sustainability, Environmental Justice and Equity. Space and Policy, 6(1), 77-90.

Anderson, T. K. 2009. Kernel Density Estimation and K-means Clustering to Profile Road Accident Hotspots. Accident Analysis and Prevention 41, no. 3: 359-64.

Anselin, L., Syabri, I. and Y. Kho. 2006. GeoDa: An Introduction to Spatial Data Analysis. Geographical Analysis 38 (1), 5-22.

Bates, L. 2013. City of Portland, Bureau of Planning and Sustainability. Gentrification and Displacement Study: implementing an equitable inclusive development strategy in the context of gentrification. Last Accessed 16 March 2018 at https://www.portlandoregon.gov/bps/article/508122

Beven, K. J. \& Kirkby, M. J. 1979. A Physically Based, Variable Contributing Area Model of Basin Hydrology / Un Modèle à Base Physique De Zone D'appel Variable De L'hydrologie Du Bassin Versant. Hydrological Sciences Bulletin. Bulletin Des Sciences Hydrologiques. 24, 1: 43-69.

Chakraborty, J., Collins, T. W., \& Grineski, S. E. 2016. Environmental justice research: Contemporary issues and emerging topics. International Journal of Environmental Research and Public Health, 13(11), 1.

Chang, H. 2007. Comparative streamflow characteristics in urbanizing basins in the Portland Metropolitan Area, Oregon, USA. Hydrological Processes 21.2: 211-222.

Chang, H., \& Franczyk, J. 2008. Climate Change, Land-Use Change, and Floods: Toward an Integrated Assessment. Geography Compass, 2(5), 1549-1579.

Chang, H., Lafrenz, M., Jung, I.W., Figliozzi, M., Platman, D., and Pederson, C. 2010. Potential Impacts of Climate Change on Flood-Induced Travel Disruptions: A Case Study of Portland, Oregon, USA. Annals of the Association of American Geographers 100, no. 4:938-952.

Chun, H., Chi, S., Hwang, B.G. 2017. A Spatial Disaster Assessment Model of Social Resilience Based on Geographically Weighted Regression. Sustainability. 9, no. 12: 2222.

City of Portland, Bureau of Environmental Services. 2010. Portland Plan: Stormwater Management and Infrastructure. Last accessed 25 May 2018 at http://www.portlandonline.com/portlandplan/index.cfm?a=298496\&c=5225 4

2011. Rooftops to Rivers II. A Case Study of How Green Infrastructure is Helping Manage Urban Stormwater Challenges. Last accessed 19 July 
2018 at

https://assets.nrdc.org/sites/default/files/RooftopstoRivers_Portland.pdf

2015. Underground Injection Control Management Plan. Stormwater Underground Injection Control. Last accessed 18 July 2018 at https://www. portlandoregon.gov/bes/article/561277

Cooley, A. \& Chang, H. 2017. Precipitation Intensity Trend Detection using Hourly and Daily Observations in Portland, Oregon. Climate, 5(1), 10.

Cornell University. 2018. Defining Citizen Science: Working Group Synthesis Report. Citizen Science Toolkit Conference. Ithaca, NY. Last accessed 18 July 2018 at

http://www.birds.cornell.edu/citscitoolkit/about/SYNTHESIS\%20Defining\% 20Citizen\%20Science.pdf

Cutter, S. L., \& Finch, C. 2007. Temporal and Spatial Changes in Social Vulnerability to Natural Hazards. Proceedings of the National Academy of Sciences of the United States of America. 105, no. 7, 2301-306.

Daly, C. 1994. A Statistical-topographic Model for Mapping Climatological Precipitation over Mountainous Terrain. Journal of Applied Meteorology 33, no. 2: 140-58

DiSalvo, A., Fukuda, J. and Ramsey, J. 2017. Street Tree Inventory Report: City of Portland. Last accessed 26 May 2018 at https://www.portlandoregon.gov/parks/article/638773

Denton, F. 2002. Climate change vulnerability, impacts, and adaptation: Why does gender matter? Gender \& Development, 10:2, 10-20.

Douglas, E. M., Kirshen, P. H., Paolisso, M., Watson, C., Wiggin, J., Enrici, A., \& Ruth, M. 2012. Coastal flooding, climate change and environmental justice: Identifying obstacles and incentives for adaptation in two metropolitan Boston Massachusetts communities. Mitigation and Adaptation Strategies for Global Change, 17(5), 537-562.

Dunn, C. E. 2007. Participatory GIS -- a people's GIS? Progress in Human Geography, 31(5), 616-637.

Elliott, J. R. \& Pais, J. 2006. Race, Class, and Hurricane Katrina: Social differences in human responses to disaster, In Social Science Research, Volume 35, Issue 2: 295-321

EPA. United States Environmental Protection Agency. 2017. What is Green Infrastructure? Last Accessed 17 March 2018 at https://www.epa.gov/green-infrastructure/what-green-infrastructure

ESRI. 2017. ArcGIS Desktop: Stretch Function. Last accessed 26 May 2018 at http://desktop.arcgis.com/en/arcmap/latest/manage-data/raster-andimages/stretch-function.htm

ArcGIS Desktop: Release 10.5.1 Redlands, CA: Environmental Systems Research Institute. 
Fazeli, H. R., Amerudin, S., Abd Rahman, M. Z., \& Said, M. N. 2015. A study of volunteered geographic information (VGI) assessment methods for flood hazard mapping: A review. J. Teknol. Jurnal Teknologi, 75(10), 127-134.

Fiedler, F.R. 2003. Simple, Practical Method for Determining Station Weights Using Thiessen Polygons and Isohyetal Maps. Journal of Hydrologic Engineering. 8(4): 219-221

Forgey, F. 1994. Effect of Foreclosure Status on Residential Selling Price. The Journal of Real Estate Research. 9, no. 3: 313.

Ge, Y., Dou, W., \& Liu, N. 2017. Planning Resilient and Sustainable Cities: Identifying and Targeting Social Vulnerability to Climate Change. Sustainability. 9(8), 1394.

Grabs, T., Seibert, J., Bishop, K. and H. Laudon. 2009. Modeling Spatial Patterns of Saturated Areas: A Comparison of the Topographic Wetness Index and a Dynamic Distributed Model. Journal of Hydrology 373, no. 1-2: 15-23.

Grineski, S. E., Collins, T.W., Ford, P., Fitzgerald, R., Aldouri, R., VelázquezAngulo, G., De Lourdes Romo Aguilar, M. and Lu., D. 2012. Climate Change and Environmental Injustice in a Bi-national Context. Applied Geography. 33: 25-35.

Guerreiro, S. B., Glenis, V., Dawson, R. J., \& Kilsby, C. 2017. Pluvial flooding in European cities-A continental approach to urban flood modelling. Water, 9(4), 296.

Hailegeorgis, T.T. \& Alfredsen, K. 2017. Analyses of extreme precipitation and runoff events including uncertainties and reliability in design and management of urban water infrastructure, In Journal of Hydrology, Volume 544: 290-305

Heynen, N., Perkins, H.A. and P. Roy. 2006. The Political Ecology of Uneven Urban Green Space. Urban Affairs Review. 42, no. 1: 3-25.

Hung, K. C., Kalantari, M., \& Rajabifard, A. 2016. Methods for assessing the credibility of volunteered geographic information in flood response: A case study in Brisbane, Australia. Applied Geography, 68, 37-47.

HYDRA Rainfall Network. 2017. City of Portland Bureau of Environmental Services. Last Accessed 22 June 2018 at https://or.water.usgs.gov/nonusgs/bes/

Jalayer, R., Paola, G., Manfredi, G., Topa, Y., Yeshitela, N., Cavan, L., and Printz, R. 2014. Probabilistic GIS-based method for delineation of urban flooding risk hotspots: Natural Hazards, v 73: 975-1001

Jenkins, K., Surminski, S., Hall, J., and F. Crick, Assessing surface water flood risk and management strategies under future climate change: Insights from an Agent-Based Model, In Science of The Total Environment, Volume 595, 2017: 159-168

Klonner, C., Marx, S., Usón, T., Porto de Albuquerque, J., \& Höfle, B. 2016. Volunteered geographic information in natural hazard analysis: a systematic literature review of current approaches with a focus on 
preparedness and mitigation. ISPRS International Journal of GeoInformation, 5(7), 103.

Koks E.E., B. Jongman, T.G. Husby, W.J.W. Botzen. 2015. Combining hazard, exposure and social vulnerability to provide lessons for flood risk management, In Environmental Science \& Policy, Volume 47: 42-52

Krellenberg, K., \& J. Welz. 2017. Assessing Urban Vulnerability in the Context of Flood and Heat Hazard: Pathways and Challenges for Indicator-Based Analysis. Social Indicators Research 132, no. 2: 709-731.

Matthews, S. A., \& Yang, T. 2012. Mapping the results of local statistics: Using geographically weighted regression. Demographic Research, 26, I, II: 151166.

Moftakhari, H. R, AghaKouchak, A., Sanders, B.F., Allaire, M. and R. A. Matthew. 2018. What Is Nuisance Flooding? Defining and Monitoring an Emerging Challenge. Water Resources Research. 54. https://doi.org/10.1029/2018WR022828

Moftakhari, H. R., AghaKouchak, A., Sanders, B.F. and R.A. Matthew. 2017. Cumulative Hazard: The Case of Nuisance Flooding. Earth's Future. 5, no. 2: 214-23.

Moftakhari, H. R., AghaKouchak, A., Sanders, B.F., Feldman, D.L., Sweet, W., Matthew, R.A., and A. Luke. 2015 Increased Nuisance Flooding along the Coasts of the United States Due to Sea Level Rise: Past and Future. Geophysical Research Letters. 42, no. 22: 9846-852.

McKenzie, B. S. 2013. Neighborhood Access to Transit by Race, Ethnicity, and Poverty in Portland, OR. City \& Community. 12, no. 2: 134-55

National Oceanic and Atmospheric Administration (NOAA). 2015. Local Climate Data from Portland Airport: Climatic Summary and Station History. U.S. Department of Commerce. Last Accessed 4 December 2017 at http://www.wrh.noaa.gov/pqr/pdxclimate/introduction.pdf

Laenen, A. \& D. A. Dunnette. 2017. River Quality: Dynamics and Restoration. CRC Press LCC: Lewis Publishers. New York, NY.

Larson, K and D. Lach. 2010. Equity in Urban Water Governance through Participatory, Place-Based Approaches. Natural Resources Journal. 50(2), 407-430.

Lynn, K. 2017. Rising recreancy: Flood control and community relocation in Houston, TX, from an environmental justice perspective. Local Environment, 22(3), 321-334

Oregon Institute for Water and Watersheds. 2012. Oregon Climate Change Research Institute. Water and Climate in the Pacific Northwest. Oregon State University, Corvallis, OR. Last accessed 30 October 2017 at http://water.oregonstate.edu/sites/water.oregonstate.edu/files/water and climate in the pacific northwest v3.pdf

Oregon Metro Regional Land Information System (RLIS). 2018. 
Taxlots. Last accessed 14 June 2018 at http://rlisdiscovery.oregonmetro.gov/?resourcelD=99

Multifamily Housing Inventory. Accessed 14 June 2018 at http://rlisdiscovery.oregonmetro.gov/?action=viewDetail\&layerID=2364

The Oregon Historical Society. 2018. Last accessed 26 May 2018 at http://www.ohs.org/museum/exhibits/vanport.cfm https://oregonencyclopedia.org/articles/willamette flood 1894 /\#.WwnaY $\mathrm{dMvxSw}$ https://oregonencyclopedia.org/articles/willamette river flood of 1996/\#. WwnahtMvxSw

Phillips, J., \& E. Goodstein. 2000. Growth Management and Housing Prices: The Case of Portland, Oregon. Contemporary Economic Policy. 18, no. 3: 33444.

Ralph, F. M., \& Dettinger, M. D. 2012. Historical and national perspectives on extreme west coast precipitation associated with atmospheric rivers during December 2010. Bulletin of the American Meteorological Society, 93(6), 783-790.

Rasch, R. Income Inequality and Urban Vulnerability to Flood Hazard in Brazil. 2017. Social Science Quarterly.,98(1), 299-325

Romero-Lankao, P., Hughes, S., Qin, H., Hardoy, J., Rosas-Huerta, A., Borquez, R., and A. Lampis. 2014. Scale, urban risk and adaptation capacity in neighborhoods of Latin American cities, In Habitat International, Volume 42: $224-235$

Rosenzweig, B., McPhillips, L., Chang, H., Cheng, C., Welty, C., Matsler, M., and Iwaniec, D. 2018. Urban pluvial flood risk and opportunities for resilience, Wires Water. Manuscript submitted for publication.

Röthlisberger V., Zischg, A.P. Keiler, M. 2017. Identifying spatial clusters of flood exposure to support decision making in risk management, In Science of The Total Environment, Volume 598: 593-603

RStudio Team. 2016. RStudio: Integrated Development for R. RStudio, Inc., Boston, MA http://www.rstudio.com/.

TrackIT. 2017. The City of Portland, Oregon. Last Accessed 30 October 2017 at https://www.portlandoregon.gov/trackit/index.cfm

Sansom, G., Parras, J., Parras, A., Nieto, Y., Arellano, Y., Berke, P., McDonald, T., Shipp, E., and Horney, J. A. 2017. The Impacts of Exposure to Environmental Risk on Physical and Mental Health in a Small Geographic Community in Houston, TX. Journal of Community Health. 42(4), 813.

Schlosberg, D. 2004. Reconceiving Environmental Justice: Global Movements and Political Theories. Environmental Politics. 13, no. 3: 517-40.

Seibert, J., \& B. L. McGlynn. 2007. A New Triangular Multiple Flow Direction Algorithm for Computing Upslope Areas from Gridded Digital Elevation Models. Water Resources Research. 43, no. 4. 
Singh, B. 2014. Flood Hazard Mapping with Participatory GIS. Environment and Urbanization Asia, 5(1), 161-173.

Usón, T. J., Klonner, C., \& Höfle, B. 2016. Using participatory geographic approaches for urban flood risk in Santiago de Chile: Insights from a governance analysis. Environmental Science \& Policy, 66: 62-72.

U.S. Census Bureau. 2016. Quick Facts, Portland city, Oregon. People: Population Estimates, July 1, 2016. Last Accessed 9 November 2017 https://www.census.gov/quickfacts/fact/table/portlandcityoregon/PST0452 1

Wu, Y., Giri, S. and Z. Qiu. 2016. Understanding the Spatial Distribution of Hydrologic Sensitive Areas in the Landscape Using Soil Topographic Index Approach. International Soil and Water Conservation Research, no. 4: 278-83.

Wang, C., Du, S., Wen, J., Zhang, M., Gu, H., Shi, Y., \& Xu, H. 2017. Analyzing explanatory factors of urban pluvial floods in Shanghai using geographically weighted regression. Stochastic Environmental Research and Risk Assessment, 31(7), 1777-1790.

Xu, J., \& Nyerges, T. L. 2017. A framework for user-generated geographic content acquisition in an age of crowdsourcing. Cartography and Geographic Information Science, 44(2), 98-112.

Ye, S., Li, H.Y., Leung, L.R., Guo, J., Ran, Q., Demissie, Y. and M. Sivapalan. 2017. Understanding Flood Seasonality and Its Temporal Shifts within the Contiguous United States. Journal of Hydrometeorology. 18, no. 7: 19972009.

Youngman, N. 2009. Understanding Disaster Vulnerability: Floods and Hurricanes. In Kenneth A. Gould and Tammy L. Lewis (Eds.), Twenty Lessons in Environmental Sociology. (pp. 176-190) New York, NY: Oxford University Press. 


\section{Appendix. 39 HYDRA Rain Gages}

\begin{tabular}{|c|c|c|c|c|}
\hline Station Name & $\begin{array}{l}\text { Station } \\
\text { Number }\end{array}$ & Location & $\begin{array}{l}\text { Period of } \\
\text { Record }\end{array}$ & Source \\
\hline Portland Fire Bureau & 1 & 55 SW Ash St. & $\begin{array}{l}\text { 01/01/2010- } \\
2 / 22 / 2017\end{array}$ & USGS \\
\hline Skyline School & 2 & $\begin{array}{l}11536 \text { NW Skyline } \\
\text { Blvd. }\end{array}$ & $\begin{array}{l}01 / 01 / 2010- \\
2 / 22 / 2017\end{array}$ & USGS \\
\hline Sylvania PCC & 4 & $\begin{array}{l}\text { SS Bldg., } 12000 \text { SW } \\
\text { 49th Ave. }\end{array}$ & $\begin{array}{l}\text { 01/01/2010- } \\
2 / 22 / 2017\end{array}$ & USGS \\
\hline $\begin{array}{l}\text { Mt. Tabor } \\
\text { Maintenance Yard }\end{array}$ & 6 & 6437 SE Division St. & $\begin{array}{l}01 / 01 / 2010- \\
2 / 22 / 2017\end{array}$ & USGS \\
\hline Hayden Island & 7 & $\begin{array}{l}1740 \text { N Jantzen } \\
\text { Beach Ctr. }\end{array}$ & $\begin{array}{l}01 / 01 / 2010- \\
2 / 22 / 2017\end{array}$ & USGS \\
\hline Collins View & 10 & $\begin{array}{l}9806 \text { SW Boones } \\
\text { Ferry Rd. }\end{array}$ & $\begin{array}{l}01 / 01 / 2010 \\
2 / 22 / 2017\end{array}$ & USGS \\
\hline Fernwood School & 12 & 3255 NE Hancock St. & $\begin{array}{l}01 / 01 / 2010- \\
2 / 22 / 2017\end{array}$ & USGS \\
\hline Kelly School & 14 & 9030 SE Cooper St. & $\begin{array}{l}01 / 01 / 2010- \\
2 / 22 / 2017\end{array}$ & USGS \\
\hline Gresham Fire Dept. & 20 & $\begin{array}{l}1333 \text { NW Eastman } \\
\text { Pkwy. }\end{array}$ & $\begin{array}{l}01 / 01 / 2010- \\
2 / 22 / 2017\end{array}$ & USGS \\
\hline Vernon School & 41 & $\begin{array}{l}2044 \text { NE Killingsworth } \\
\text { St. }\end{array}$ & $\begin{array}{l}01 / 01 / 2010- \\
2 / 22 / 2017\end{array}$ & USGS \\
\hline $\begin{array}{l}\text { Open Meadows } \\
\text { School }\end{array}$ & 48 & 7602 N Emerald Ave. & $\begin{array}{l}01 / 01 / 2010- \\
2 / 22 / 2017\end{array}$ & USGS \\
\hline Bonny Slope School & 58 & $\begin{array}{l}10351 \text { NW Thompson } \\
\text { Rd. }\end{array}$ & $\begin{array}{l}01 / 01 / 2010- \\
2 / 22 / 2017\end{array}$ & USGS \\
\hline Harney & 64 & 2033 SE Harney St. & $\begin{array}{l}01 / 01 / 2010- \\
2 / 22 / 2017\end{array}$ & USGS \\
\hline Shipyard & 82 & 8900 N Sever Road & $\begin{array}{l}01 / 01 / 2010- \\
2 / 22 / 2017\end{array}$ & USGS \\
\hline Columbia IPS & 107 & $\begin{array}{l}5001 \text { N Columbia } \\
\text { Blvd. }\end{array}$ & $\begin{array}{l}01 / 01 / 2010- \\
2 / 22 / 2017\end{array}$ & USGS \\
\hline Airport Way \#2 & 111 & $\begin{array}{l}14614 \text { NE Airport } \\
\text { Way }\end{array}$ & $\begin{array}{l}01 / 01 / 2010- \\
2 / 22 / 2017\end{array}$ & USGS \\
\hline Mallory & 115 & 8030 NE Mallory Ave. & $\begin{array}{l}01 / 01 / 2010- \\
2 / 22 / 2017\end{array}$ & USGS \\
\hline Albina & 117 & 2920 N Larrabee Ave. & $\begin{array}{l}01 / 01 / 2010- \\
2 / 22 / 2017\end{array}$ & USGS \\
\hline Yeon & 121 & 3395 NW Yeon St. & $\begin{array}{l}01 / 01 / 2010- \\
2 / 22 / 2017\end{array}$ & USGS \\
\hline Simmons & 139 & $\begin{array}{l}16001 \text { N Simmons } \\
\text { Rd. }\end{array}$ & $\begin{array}{l}01 / 01 / 2010- \\
2 / 22 / 2017\end{array}$ & USGS \\
\hline $\begin{array}{l}\text { Pleasant Valley } \\
\text { School }\end{array}$ & 145 & 17625 SE Foster Rd. & $\begin{array}{l}01 / 01 / 2010- \\
2 / 22 / 2017\end{array}$ & USGS \\
\hline Beaumont School & 152 & $\begin{array}{l}4043 \text { NE Fremont } \\
\text { Ave. }\end{array}$ & $\begin{array}{l}\text { 01/01/2010- } \\
2 / 22 / 2017\end{array}$ & USGS \\
\hline Post Office & 159 & 7660 NE Airport Way & $\begin{array}{l}01 / 01 / 2010- \\
2 / 22 / 2017\end{array}$ & USGS \\
\hline
\end{tabular}




\begin{tabular}{|c|c|c|c|c|}
\hline WPCL & 160 & $\begin{array}{l}6543 \text { N Burlington } \\
\text { Ave. }\end{array}$ & $\begin{array}{l}\text { 01/01/2010- } \\
2 / 22 / 2017\end{array}$ & USGS \\
\hline Sylvan School & 161 & 1849 SW 58th Ave. & $\begin{array}{l}01 / 01 / 2010- \\
2 / 22 / 2017\end{array}$ & USGS \\
\hline Eco Roof & 164 & SW 12th and Clay & $\begin{array}{l}\text { 01/01/2010- } \\
2 / 22 / 2017\end{array}$ & USGS \\
\hline Sunnyside School & 171 & 3421 SE Salmon St. & $\begin{array}{l}01 / 01 / 2010- \\
2 / 22 / 2017\end{array}$ & USGS \\
\hline $\begin{array}{l}\text { Maplewood } \\
\text { Elementary School }\end{array}$ & 172 & 7452 SW 52nd Ave. & $\begin{array}{l}\text { 01/01/2010- } \\
2 / 22 / 2017\end{array}$ & USGS \\
\hline $\begin{array}{l}\text { Metro Learning } \\
\text { Center }\end{array}$ & 173 & 2033 NW Glisan St. & $\begin{array}{l}01 / 01 / 2010- \\
2 / 22 / 2017\end{array}$ & USGS \\
\hline Arleta School & 174 & 5109 SE 66th Ave. & $\begin{array}{l}\text { 01/01/2010- } \\
2 / 22 / 2017\end{array}$ & USGS \\
\hline Glencoe School & 175 & 825 SE 51st Ave. & $\begin{array}{l}01 / 01 / 2010- \\
2 / 22 / 2017\end{array}$ & USGS \\
\hline Multnomah & 181 & $\begin{array}{l}501 \text { SE Hawthorne } \\
\text { Blvd. }\end{array}$ & $\begin{array}{l}\text { 01/01/2010- } \\
2 / 22 / 2017\end{array}$ & USGS \\
\hline Children's Museum & 192 & 4015 SW Canyon Rd. & $\begin{array}{l}\text { 01/01/2010- } \\
2 / 22 / 2017\end{array}$ & USGS \\
\hline $\begin{array}{l}\text { Astor Elementary } \\
\text { School }\end{array}$ & 193 & $5601 \mathrm{~N}$ Yale St. & $\begin{array}{l}01 / 01 / 2010- \\
2 / 22 / 2017\end{array}$ & USGS \\
\hline Swan Island & 204 & Near Willamette River & $\begin{array}{l}\text { 01/01/2010- } \\
2 / 22 / 2017\end{array}$ & USGS \\
\hline Madison & 213 & 2735 NE 82nd Ave. & $\begin{array}{l}\text { 01/01/2010- } \\
2 / 22 / 2017\end{array}$ & USGS \\
\hline OPB & 214 & SW Macadam Ave. & $\begin{array}{l}\text { 01/01/2010- } \\
2 / 22 / 2017\end{array}$ & USGS \\
\hline Park SE Yard & 217 & 5669 SE 136th Ave. & $\begin{array}{l}\text { 01/01/2010- } \\
2 / 22 / 2017\end{array}$ & USGS \\
\hline Walmart Eco Roof & 220 & $\begin{array}{l}1123 \text { N Hayden } \\
\text { Meadows Dr. }\end{array}$ & $\begin{array}{l}\text { 01/01/2010- } \\
2 / 22 / 2017\end{array}$ & USGS \\
\hline
\end{tabular}

